\title{
Imaging of innate immunity activation in vivo with a redox-tuned PET reporter
}

\author{
Federica Pisaneschi ${ }^{1,3}{ }^{1,}$, Seth T. Gammon ${ }^{10}{ }^{1,3}$, Vincenzo Paolillo², Sarah A. Qureshy ${ }^{1}$ and \\ David Piwnica-Worms ${ }^{1 凶}$
}

\begin{abstract}
High-redox-potential reactive oxygen species and reactive nitrogen species (ROS/RNS), generated by NADPH oxidase-2 (NOX2), myeloperoxidase (MPO) and related enzymes, are key effector molecules of innate immunity. High-redox-potential radicals are difficult to distinguish by imaging from less potent ROS/RNS functioning as background biological signaling molecules. Here we present 4-[18F]fluoro-1-naphthol ( $\left.\left.{ }^{18} \mathrm{~F}\right] 4 \mathrm{FN}\right)$, a redox-tuned radiopharmaceutical that selectively binds proteins and cells when oxidized by products of human $\mathrm{MPO}$ plus $\mathrm{H}_{2} \mathrm{O}_{2}$, but not $\mathrm{H}_{2} \mathrm{O}_{2}$ alone, and can be detected using positron emission tomography (PET). Activating HL-60 neutrophil-like human cells with phorbol ester (PMA) caused [ ${ }^{18}$ F]4FN retention five-fold over unstimulated cells. An MPO-specific inhibitor (4-ABAH) blocked cellular retention by more than $95 \%$. [ $\left.{ }^{18} \mathrm{~F}\right] 4 \mathrm{FN}$ PET/CT imaging discriminated inflammatory foci in vivo in three murine models of activated innate immunity: endotoxin-induced toxic shock, PMA-induced contact dermatitis and lipopolysaccharide-induced ankle arthritis. 4-ABAH and $\mathrm{Cybb}^{-/-}\left(\mathrm{Nox2}^{-/-}\right)$gene $^{-}$ deletion strongly abrogated $\left[{ }^{18} \mathrm{~F}\right] 4 \mathrm{FN}$ retention in vivo. Thus, $\left[{ }^{18} \mathrm{~F}\right] 4 \mathrm{FN}$ shows promise as a robust reporter of innate immunity activation by PET/CT.
\end{abstract}

C ells of the innate immune system (for example, neutrophils, macrophages, natural killer cells, mast cells and dendritic cells) detect pathogens largely through germline-encoded pattern recognition receptors (PRRs) expressed either on host cell surfaces or within distinct intracellular compartments ${ }^{1}$. PRRs detect and respond to molecules common to microbial and viral infections, often known as pathogen-associated molecular patterns, linked to microbial pathogens (for example, lipopolysaccharide (LPS), mannose, double-stranded RNA and glycopeptides) and danger-associated molecular patterns ${ }^{2}$. Once engaged, PRRs activate signaling cascades, producing new transcriptional, metabolic and functional states. In a critical subset of innate immune cells, including neutrophils, eosinophils and macrophages, an essential biochemical mediator of activated innate immunity is the respiratory burst (oxidative burst), the rapid local production and release of ROS and RNS. Superoxide $\left(\mathrm{O}_{2}{ }^{-}\right)$is generated by NOX2 and rapidly converted by superoxide dismutase to hydrogen peroxide $\left(\mathrm{H}_{2} \mathrm{O}_{2}\right)$, which activates the reaction center of MPO (compound I) ${ }^{3}$. Activated MPO can oxidize chloride to hypochlorite, cascading into other high-energy RONS, including singlet oxygen ${ }^{4}$. Similarly, nitric oxide (NO) is produced in activated macrophages (particularly murine macrophages) or associated members of innate immunity by inducible or endothelial NO synthase-iNOS or eNOS, respectivel ${ }^{5,6}$. Overall, these radical generating systems are biochemically interconnected. For example, NO can rapidly react with other $\mathrm{O}_{2}$ free radicals (for example, $\mathrm{O}_{2}{ }^{-}$) to generate a diverse array of reactive nitrogen species (peroxynitrite, $\left.\mathrm{ONOO}^{-}\right)^{7}$, and $\mathrm{H}_{2} \mathrm{O}_{2}$ can react with $\mathrm{Fe}^{2+}$ to produce hydroxyl radicals 8 . The functional utility of reactive oxygen species in defense is an ancient and deeply conserved pathway and, indeed, precedes the adaptive immune response ${ }^{9,10}$. Many components of cellular innate immunity, when activated, characteristically leverage the local production of a series of highly reactive species with redox potentials (E) generally $>1 \mathrm{~V}$ (Table 1 ).
For example, MPO and eosinophil peroxidase, key effector enzymes in innate immunity, leverage highly reactive iron-oxygen radicals within their respective active sites (for example, compound I and compound II; E $>1 \mathrm{~V}$ ) for direct oxidation of halides and of a variety of organic molecules (typically aromatic species, including tyrosine, catechols, phenols, luminol and naphthols) ${ }^{11}$. These high-energy reactive radical species can be contrasted with other forms of less potent RONS $(\mathrm{E}<0.5)$, including $\mathrm{NO}$ and single-electron reactive $\mathrm{H}_{2} \mathrm{O}_{2}$, which are produced under a variety of conditions outside of activation of innate immunity. Due to their lower redox potential and reactivity, they typically function as 'long' distance signaling molecules ${ }^{12}$. Redox tuning between these standard reduction potentials might provide a novel discrimination filter for the selective detection of the activation of key members of innate immunity broadly versus underlying 'background' sources of signaling homeostasis. We identified a core pharmacophore, 1-naphthol, with chemical reactivity favoring higher-redox-potential RONS (hydroxyl radical and hypochlorous acid) while functionally inert to lower-redox-potential RONS ( $\mathrm{NO}$ and single-electron $\mathrm{H}_{2} \mathrm{O}_{2}$ ).

Here we report $\left[{ }^{18} \mathrm{~F}\right] 4 \mathrm{FN}$, a novel radiopharmaceutical for imaging the activation state of innate immunity by PET/CT based upon the 1-naphthol pharmacophore. $\left[{ }^{18} \mathrm{~F}\right] 4 \mathrm{FN}$ is an ${ }^{18} \mathrm{~F}$-radiolabeled bio-isostere of 4-chloro-1-naphthol $(4 \mathrm{CN})$ and $\left[{ }^{14} \mathrm{C}\right] 1$-naphthol. $4 \mathrm{CN}$ has been used as a histochemical stain for neutrophils and MPO ex vivo ${ }^{13}$. $\left[{ }^{14} \mathrm{C}\right] 1$-naphthol is oxidized and trapped on proximate proteins or macromolecules, including the ROS-producing enzymes ${ }^{14-16}$. Significantly, the redox potential of 1-naphthoxy radical is $0.59 \mathrm{~V}$, which is well above hydrogen peroxide $\left(1 \mathrm{e}^{-}\right)$and NO but below MPO/compound 1 and high-energy effectors, tuned for selective reactivity with innate immunity (Table 1 ). $\left.{ }^{18} \mathrm{~F}\right] 4 \mathrm{FN}$-derived redox reactive products in vivo would be predicted to undergo rapid macromolecular conjugation reactions, thereby locally trapping the radiotracer to generate 'hot spot' PET signals compared

'Department of Cancer Systems Imaging, The University of Texas MD Anderson Cancer Center, Houston, TX, USA. ${ }^{2}$ Center for Advanced Biomedical Imaging, The University of Texas MD Anderson Cancer Center, Houston, TX, USA. ${ }^{3}$ These authors contributed equally: Federica Pisaneschi, Seth T. Gammon. 凶e-mail: dpiwnica-worms@mdanderson.org 


\begin{tabular}{|c|c|c|}
\hline Redox couple (number of electrons) & $\begin{array}{l}\text { Reduction potential } \\
(\mathrm{E}, \mathrm{V} \text { vs } \mathrm{NHE})\end{array}$ & Reference \\
\hline $\mathrm{OH}^{\bullet}+\mathrm{H}^{+} / \mathrm{H}_{2} \mathrm{O}\left(1 \mathrm{e}^{-}\right)$ & 2.3 & 48 \\
\hline $\mathrm{HOCl} / \mathrm{H}_{2} \mathrm{O}, \mathrm{Cl}^{-}\left(2 \mathrm{e}^{-}\right)$ & 1.48 & 49 \\
\hline Peroxynitrite $/ \mathrm{NO}_{2}\left(1 \mathrm{e}^{-}\right)$ & $1.4(\mathrm{pH}=7)$ & 50 \\
\hline MPO compound I/compound II $\left(1 e^{-}\right)$ & $1.35(\mathrm{pH}=7)$ & 51 \\
\hline MPO compound I/native MPO (2e-) & $1.16(\mathrm{pH}=7)$ & 51 \\
\hline MPO compound II/native MPO $\left(1 e^{-}\right)$ & $0.97(\mathrm{pH}=7)$ & 51 \\
\hline $\mathrm{O}_{2} \cdot / / \mathrm{H}_{2} \mathrm{O}_{2}\left(1 \mathrm{e}^{-}\right)$ & $0.9(\mathrm{pH}=7)$ & 48 \\
\hline $\mathrm{OCl}^{-} / \mathrm{Cl}_{2}\left(1 \mathrm{e}^{-}\right)$ & 0.89 & 49 \\
\hline Singlet oxygen/superoxide anion $\left(1 \mathrm{e}^{-}\right)$ & 0.81 & 52 \\
\hline Naphthol radical/1-naphthol $\left(1 \mathrm{e}^{-}\right)$ & 0.59 & 53 \\
\hline $\mathrm{OCl}^{-}+\mathrm{H}_{2} \mathrm{O} / 1 / 2 \mathrm{Cl}_{2}+2 \mathrm{OH}^{-}\left(1 \mathrm{e}^{-}\right)$ & 0.42 & 54 \\
\hline $\mathrm{H}_{2} \mathrm{O}_{2} / \mathrm{H}_{2} \mathrm{O}+\mathrm{OH}^{-}\left(1 \mathrm{e}^{-}\right)$ & 0.38 & 51 \\
\hline $\mathrm{HOCl} / \mathrm{HOCl}^{-}\left(1 \mathrm{e}^{-}\right)$ & 0.25 & 55 \\
\hline $\mathrm{O}_{2} / \mathrm{O}_{2}^{-}\left(1 \mathrm{e}^{-}\right)$ & -0.16 & 51 \\
\hline $\mathrm{NO} \cdot /{ }^{3} \mathrm{NO}^{-}\left(1 \mathrm{e}^{-}\right)$ & -0.8 & 56 \\
\hline
\end{tabular}

Higher-energy redox couples and RONS are associated with innate immunity, representing candidate species energetically poised to oxidize 1-naphthol, whereas lower-energy RONS are energetically unlikely to oxidize 1-naphthol. $\mathrm{H}_{2} \mathrm{O}_{2}$ possesses a two-electron reduction half reaction, which typically participates in high-energy RONS generation via metal-center peroxidases (for example, generation of MPO compound 1) versus lower-energy one-electron reactions ${ }^{5}$. By contrast, $\mathrm{HOCl} / \mathrm{OCl}^{-}$can exert biochemical effects via both one- and two-electron redox reactions ${ }^{58} . \mathrm{V}$, volts; $\mathrm{NHE}$, normal hydrogen electrode; ${ }^{3} \mathrm{NO}-$, triplet ground state; $1 \mathrm{e}^{-}$, one-electron reaction; $2 \mathrm{e}^{-}$, two-electron reaction.

to the surrounding background. $\left[{ }^{18} \mathrm{~F}\right] 4 \mathrm{FN}$ could provide a robust and translatable PET imaging agent for rapid, whole-body imaging and quantitative, non-invasive surveillance, potentially enabling scientists and clinicians to identify and monitor high-energy radical-mediated inflammatory foci, characteristic of activation of innate immunity-for example, multi-organ inflammation and disease, extra-pulmonary manifestations of Coronavirus Disease 2019 (COVID-19) and cytokine storm.

\section{Results}

$\left[{ }^{18} \mathrm{~F}\right] 4 \mathrm{FN}$ synthesis: aromatic copper-mediated fluorination. Boc-protected pinacol boronic ester precursor 2 was synthesized from commercially available naphthol boronate 1 by treatment with $\mathrm{Boc}_{2} \mathrm{O}$ and DMAP (Fig. 1). $\left[{ }^{18} \mathrm{~F}\right] 4 \mathrm{FN}$ was synthesized on an automated module (GE TRACERlab FX FN) in $6.8 \pm 2.5 \%(n=22)$ activity yield, by means of a copper-mediated radiofluorination of the corresponding Boc-protected pinacol boronic ester 2, followed by deprotection of 3 , purification and reformulation (Fig. 1) based on the literature procedure of Tredwell et al. ${ }^{17} \cdot\left[{ }^{18} \mathrm{~F}\right] 4 \mathrm{FN}$ was obtained in more than $99 \%$ radiochemical purity, typically more than 50 GBq per $\mu \mathrm{mol}$ and up to $140 \mathrm{GBq}$ per $\mu \mathrm{mol}$ molar activity. Identity was confirmed by co-elution of the $\left[{ }^{18} \mathrm{~F}\right] 4 \mathrm{FN}$ radioactive peak with the corresponding commercially available reference compound (Extended Data Fig. 1). $\left[{ }^{18} \mathrm{~F}\right] 4 \mathrm{FN}$ showed up to 4 -h shelf-stability in PBS $(10 \% \mathrm{EtOH})$ and was stable in mouse plasma for at least $1 \mathrm{~h}$ (Extended Data Table 1).

Testing $\left[{ }^{18} \mathrm{~F}\right] 4 \mathrm{FN}$ with MPO and NOX2 in vitro and in cellulo. First, we demonstrated MPO-mediated oxidation of $\left[{ }^{18} \mathrm{~F}\right] 4 \mathrm{FN}$ in vitro. The radiotracer experiments were monitored by concurrent bioluminescence imaging (BLI) with L-012, a validated optical reporter of RONS activity ${ }^{18}$. L-012 or $\left[{ }^{18} \mathrm{~F}\right] 4 \mathrm{FN}$ was incubated with

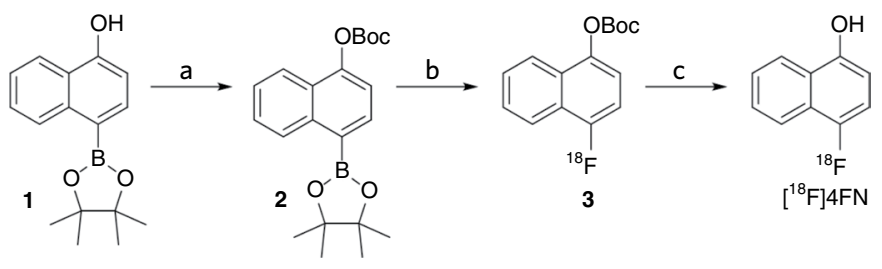

Fig. 1 | Synthesis of $\left[{ }^{18} \mathrm{~F}\right]$ 4FN. From precursor 2, $\left[{ }^{18} \mathrm{~F}\right] 4 \mathrm{FN}$ was reproducibly radiolabeled in two synthetic steps, purified and reformulated on an automated synthesis module (GE TRACERlab FX FN) with good yields, high molar activity and excellent radiochemical purity. Reagents and conditions: (a) $\mathrm{Boc}_{2} \mathrm{O}, \mathrm{DMAP}, \mathrm{CH}_{2} \mathrm{Cl}_{2}, \mathrm{rt}, 18 \mathrm{~h}(80 \%)$. (b) $\left.{ }^{18} \mathrm{~F}\right] \mathrm{KF} / \mathrm{K}_{222}, \mathrm{CuOTf}_{2}(\mathrm{Py})_{4}$, $\mathrm{DMF}, 110{ }^{\circ} \mathrm{C}, 20 \mathrm{~min}$. (c) $\mathrm{HCl} 1 \mathrm{M}, 10 \mathrm{~min}$.

water, $\mathrm{H}_{2} \mathrm{O}_{2}$ or recombinant human myeloperoxidase (rhMPO) alone plus/minus $\mathrm{H}_{2} \mathrm{O}_{2}$ for $1 \mathrm{~h}$, and the mixture was analyzed continuously by luminescence imaging (IVIS Spectrum) (L-012) or after $1 \mathrm{~h}$ by radio-HPLC $\left(\left[{ }^{18} \mathrm{~F}\right] 4 \mathrm{FN}\right)$. As expected under these conditions, L-012 luminescence resulted in more than three orders of magnitude enhanced signal upon exposure to peroxidase activity (rhMPO plus $\mathrm{H}_{2} \mathrm{O}_{2}$ ) compared to vehicle, uncatalyzed oxidation by $\mathrm{H}_{2} \mathrm{O}_{2}$ or MPO oxidase activity (rhMPO alone) (Fig. 2a,b). Analogously, when exposed to rhMPO plus $\mathrm{H}_{2} \mathrm{O}_{2}$, $\left[{ }^{18} \mathrm{~F}\right] 4 \mathrm{FN}$ was vigorously oxidized, and the parental species was now below the limit of radio-detection, whereas low-level MPO oxidase activity was detected with rhMPO alone, and non-detectable oxidation occurred with $\mathrm{H}_{2} \mathrm{O}_{2}$ or vehicle (Fig. $2 \mathrm{c}, \mathrm{d})$ ). As with $\left[{ }^{14} \mathrm{C}\right]$ naphthol, $\left[{ }^{18} \mathrm{~F}\right] 4 \mathrm{FN}$-derived radicals likely reacted with the MPO protein itself under these experimental conditions, thereby producing protein adducts retained by the guard column ${ }^{19}$ and undetected in the HPLC chromatogram (Fig. 2c,d).

The capacity of $\left[{ }^{18} \mathrm{~F}\right] 4 \mathrm{FN}$ to detect and bind activated neutrophils was tested in cellulo with HL-60 cells, a human acute myeloid leukemia cell line that can differentiate upon treatment with all-trans retinoic acid or DMSO into neutrophil-like cells ${ }^{20}$. In the present study, cellular retention of $\left[{ }^{18} \mathrm{~F}\right] 4 \mathrm{FN}$ was investigated in differentiated HL-60 cells upon activation with phorbol-12-myristate-13-acetate (PMA). PMA-inducible ROS production was cross-validated by BLI using L-012 (Fig. 2e) for each cell experiment. A nearly five-fold increase in tracer retention was observed in PMA-treated versus vehicle-treated cells (Fig. 2f), suggesting that $\left[{ }^{18} \mathrm{~F}\right] 4 \mathrm{FN}$, at tracer levels, was indeed acting as a bio-reactive bio-isostere of 1-naphthol or $4 \mathrm{CN}$.

Because $\left[{ }^{18} \mathrm{~F}\right] 4 \mathrm{FN}$ can be oxidized to reactive species via a variety of mechanisms, oxidation-induced cell retention mediated by RONS was further analyzed. The contribution of NOX2 to the retention of $\left[{ }^{18} \mathrm{~F}\right] 4 \mathrm{FN}$ was tested by pre-treating with diphenylene iodonium (DPI) ${ }^{21}$, yielding a more than $95 \%$ reduction (Fig. 2f), consistent with L-012 (Fig. 2e). Treatment with an irreversible MPO inhibitor, 4-aminobenzoic acid hydrazide (4-ABAH), yielded a $95 \%$ reduction of $\left[{ }^{18} \mathrm{~F}\right] 4 \mathrm{FN}$ retention (Fig. $2 \mathrm{f}$ ). In a control experiment with L-012 (Fig. 2e), when the same cell line was treated with PMA plus $4-\mathrm{ABAH}$, only a $65 \%$ reduction was observed, suggesting that $\left[{ }^{18} \mathrm{~F}\right] 4 \mathrm{FN}$ was more dependent upon MPO than L-012 in this model.

$\left[{ }^{18} \mathrm{~F}\right] 4 \mathrm{FN}$ characterization in vivo. Imaging acute toxic shock with $\left.{ }^{18} \mathrm{~F}\right] 4 F N$ PET. To simulate a whole-body inflammatory syndrome, LPS was administered to $\mathrm{C} 57 \mathrm{Bl} / \mathrm{N}$ mice to induce acute toxic $\operatorname{shock}^{22}$. This model is known to induce rapid neutrophil infiltration into the kidney cortex, MPO induction, ROS burst and cell death ${ }^{23}$. Mice were injected intraperitoneally (i.p.) with LPS at $20 \mathrm{mg} \mathrm{kg}^{-1}$ and imaged by PET/CT $4 \mathrm{~h}$ later with $\left[{ }^{18} \mathrm{~F}\right] 4 \mathrm{FN}\left(1 \mathrm{~h}\right.$ after $\left[{ }^{18} \mathrm{~F}\right] 4 \mathrm{FN}$ injection i.p.). Note that, at this time point, mouse behavior 
a
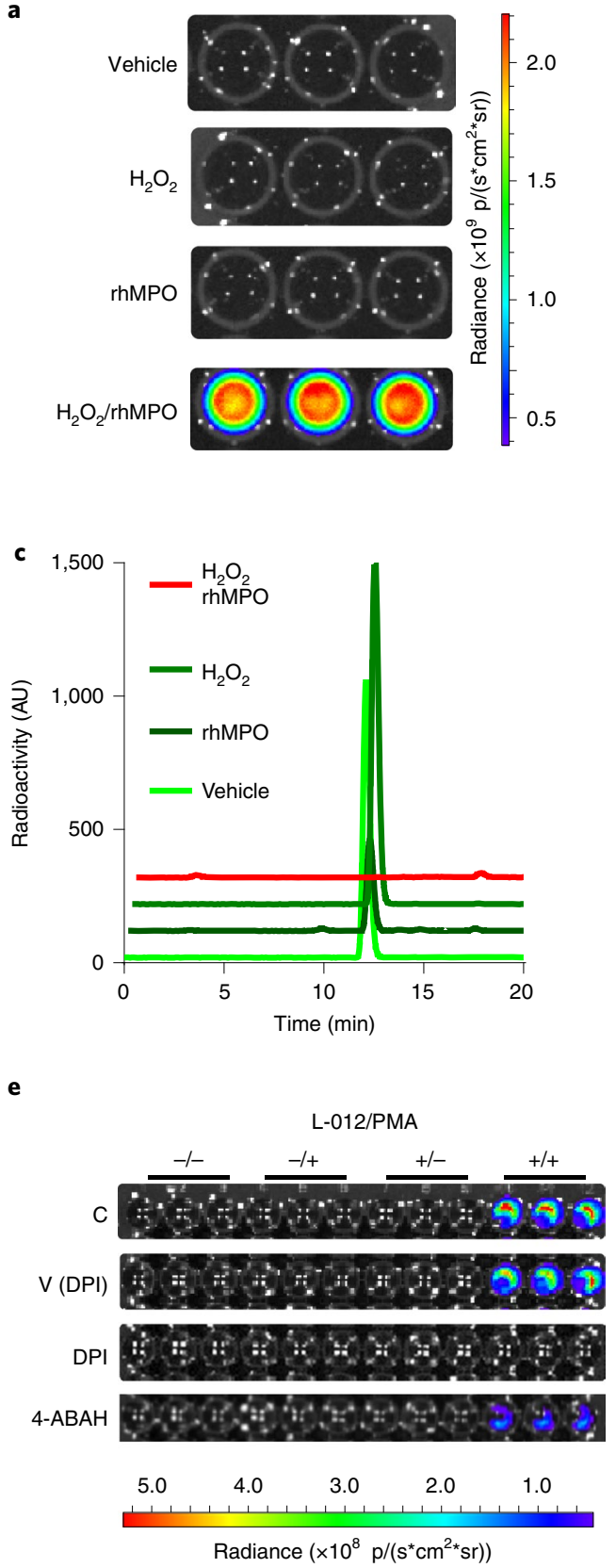

b

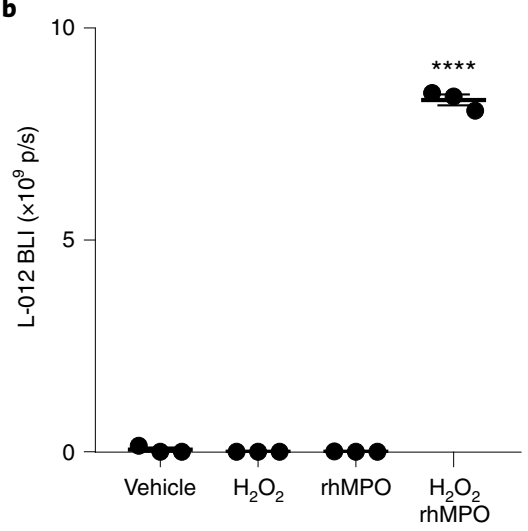

d

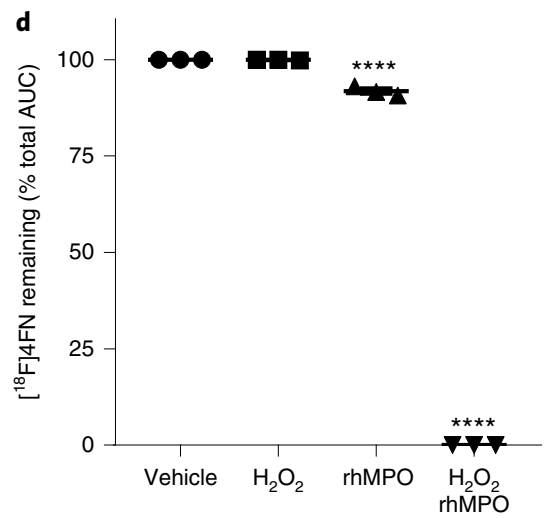

$\mathbf{f}$

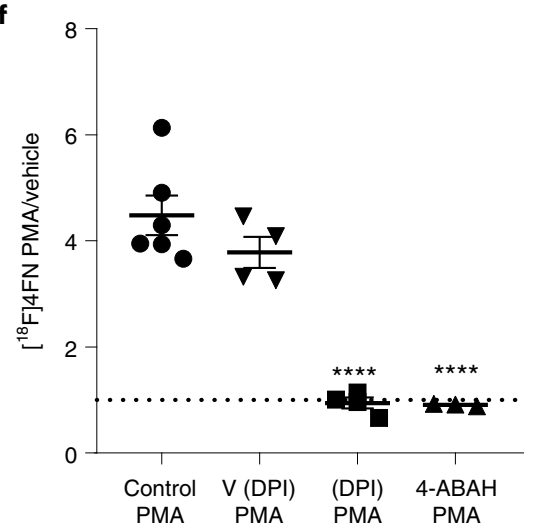

Fig. $2 \mid\left[{ }^{18} \mathrm{~F}\right] 4 \mathrm{FN}$ oxidation in vitro and in cellulo. $\left[{ }^{18} \mathrm{~F}\right] 4 \mathrm{FN}$ demonstrated robust oxidation and retention in ROS-producing models simulating innate immunity in vitro and in cellulo. a-d, L-012 or $\left[{ }^{18} \mathrm{~F}\right] 4 \mathrm{FN}$ were incubated with vehicle (water), $100 \mu \mathrm{M} \mathrm{H}_{2} \mathrm{O}_{2}$, rhMPO or $100 \mu M \mathrm{H}_{2} \mathrm{O}_{2}+\mathrm{rhMPO}$ at $37^{\circ} \mathrm{C}$ in PBS. a, Peak ROS luminescence imaged on an IVIS Spectrum for $1 \mathrm{~h}$ with L-012. b, Quantification of luminescence flux (photons per second); $n=3$ technical replicates. $\mathbf{c}$, After $1 \mathrm{~h}$ of incubation of $\left[{ }^{18} \mathrm{~F}\right] 4 \mathrm{FN}$ in the reaction mixtures, tracer reactions were quenched with equal volumes of cold ethanol, and degradation of $\left[{ }^{18} \mathrm{~F}\right] 4 \mathrm{FN}$ was characterized by radio-HPLC; $n=3$ technical replicates. $\mathbf{d}$, Percent remaining parent $\left[{ }^{18} \mathrm{~F}\right] 4 \mathrm{FN}$ quantified for each mixture (decay corrected). Example of two independent experiments; $n=3$ independent enzyme reactions. e, HL-60 cells were differentiated to yield 'neutrophil-like' cells, and, to induce ROS, cells were incubated with PMA. To test the dependence of various ROS-producing enzymes, cells were pre-incubated with a NOX2 inhibitor (DPI), vehicle for DPI (V) or an MPO inhibitor (4-ABAH). Cell aliquots from each batch were imaged with L-012 to confirm ROS production by bioluminescence. $\mathbf{f}$, In parallel, cells were incubated with $1.9 \mathrm{MBq}$ of $\left[{ }^{18} \mathrm{~F}\right] 4 \mathrm{FN}$ and washed, and retained activity was quantified. Cell retention of $\left[{ }^{18} \mathrm{~F}\right] 4 \mathrm{FN}$ is shown as the ratio of PMA-treated/vehicle-treated cells in the absence or presence of various ROS inhibitors (each point represents a 'biological' replicate of 'technical' triplicates). ${ }^{\star \star \star \star} P<0.0001$, one-way ANOVA, post hoc comparison to vehicle, two tailed, Dunnett's multiple comparison correction for $\mathbf{b}, \mathbf{c}, \mathbf{d}, \mathbf{f}$. Data are presented as mean values \pm s.e.m. AU, arbitrary unit; $A \cup C$, area under the curve.

appeared normal. At $1 \mathrm{~h}$ after injection of $\left[{ }^{18} \mathrm{~F}\right] 4 \mathrm{FN}$, all organs, as expected, showed higher retention of the PET tracer, with the largest difference observed in the kidneys (Fig. 3a,b). To confirm that the observed enhanced signal was due to actual retention of $\left[{ }^{18} \mathrm{~F}\right] 4 \mathrm{FN}$ in inflamed tissues and not simply a decrease in clearance rates, or abrogation of renal or hepatobiliary excretion, ${ }^{68} \mathrm{Ga}$-citrate was similarly tested. If a decrease in clearance was responsible for the increased organ retention, this should also be observed by 

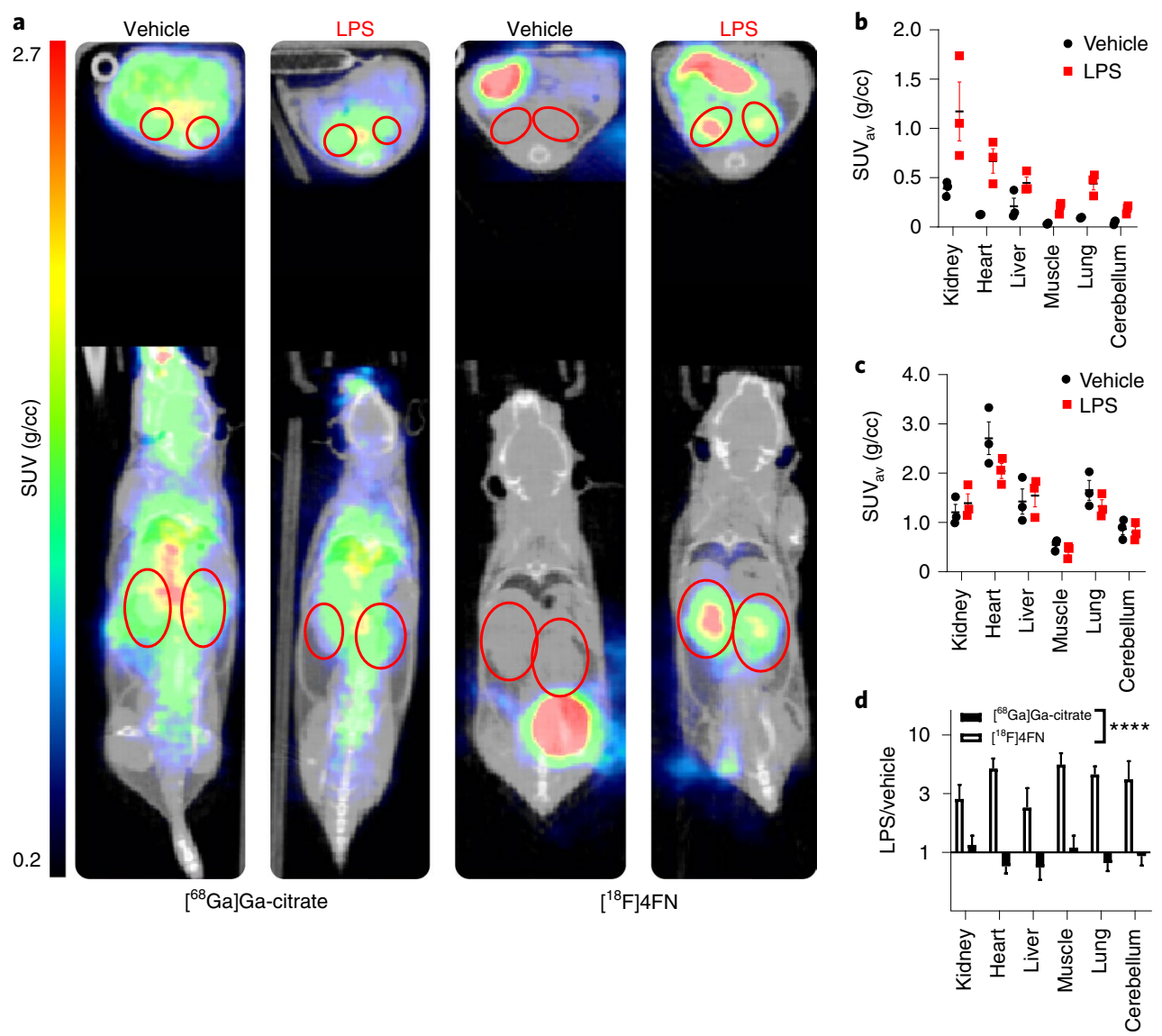

Fig. 3 | Imaging endotoxin-induced toxic shock with [ $\left.{ }^{18} \mathrm{~F}\right]$ FFN PET. In a whole-body inflammation model of acute toxic shock, $\left[{ }^{18} \mathrm{~F}\right] 4 \mathrm{FN}$ demonstrated increased retention that was greater than ${ }^{68} \mathrm{Ga}$-citrate with obvious retention in the kidney. C57BI6/N mice $(n=3$ per imaging agent per treatment) were injected with $20 \mathrm{mg} \mathrm{kg}^{-1}$ of LPS i.p. or vehicle and then, $4 \mathrm{~h}$ later, injected with $\left[{ }^{18} \mathrm{~F}\right] 4 \mathrm{FN}$ or ${ }^{68} \mathrm{Ga}$-citrate. One hour after injection of the radiotracer, mice

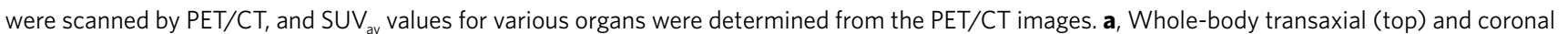
(bottom) PET/CT images of $\left[{ }^{18} \mathrm{~F}\right] 4 \mathrm{FN}$ (right panels) or ${ }^{68} \mathrm{Ga}$-citrate (left panels) from LPS-treated or vehicle-treated mice; kidneys are highlighted by red ovals. b, Image-based bio-distribution of [ $\left.{ }^{18} \mathrm{~F}\right] 4 \mathrm{FN}$ was calculated from the PET/CT data, and SUV ${ }_{\text {av }}$ values were plotted for various organs: vehicle, black;

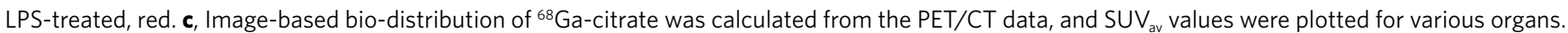
d, The fold-change in LPS/vehicle for various organs (displayed on log-scale). The fold-change in retention (LPS/vehicle) was significantly greater for $\left[{ }^{18} \mathrm{~F}\right] 4 \mathrm{FN}$ than for ${ }^{68} \mathrm{Ga}$-citrate ( ${ }^{\star \star \star \star} P<0.0001$, two-way ANOVA, two tailed, organs NS, interaction NS). Furthermore, the fold-change of ${ }^{68} \mathrm{Ga}$-citrate was 1. Data are presented as mean values \pm s.e.m. NS, not significant.

using ${ }^{68} \mathrm{Ga}$-citrate, a small molecule with mixed renal and hepatobiliary excretion. However, ${ }^{68} \mathrm{Ga}$-citrate uptake in kidney and liver, the main clearance organs, did not differ statistically between the LPS-inflamed group and the vehicle-treated group (Fig. 3c). This was even more evident when data were plotted as log-fold of treated groups versus vehicle groups: $\left[{ }^{18} \mathrm{~F}\right] 4 \mathrm{FN}$ was truly retained in the tissues, whereas the ${ }^{68} \mathrm{Ga}$-citrate log-ratio was close to or below zero (Fig. 3d). Thus, the observed increase in net organ retention with $\left[{ }^{18} \mathrm{~F}\right] 4 \mathrm{FN}$ could not be explained by simple delay of global excretion, as this would also be observed by ${ }^{68} \mathrm{Ga}$-citrate.

Imaging TLR4-stimulated arthritis with dynamic $\left[{ }^{18} \mathrm{~F}\right] 4 \mathrm{FN}$ PET. LPS was injected intra-articularly into one ankle of C57Bl6/ $\mathrm{N}$ mice, producing a focal TLR4-dependent arthritis model. The next day, after inflammation had developed, mice were imaged with $\left[{ }^{18} \mathrm{~F}\right] 4 \mathrm{FN}$ $\mathrm{PET} / \mathrm{CT}$. When compared to the non-inflamed contralateral ankle, $\mathrm{PET} / \mathrm{CT}$ images from $1 \mathrm{~h}$ after injection showed enhanced retention of $\left[{ }^{18} \mathrm{~F}\right] 4 \mathrm{FN}$ in the inflamed ankle (Fig. $4 \mathrm{a}$, left panel; $P<0.0001$ ). Most importantly, BLI of the same mice on the same day with L-012 (Fig. 4a, right panel) showed high linear correlation with $\left[{ }^{18} \mathrm{~F}\right] 4 \mathrm{FN}$ retention on a per-ankle basis (Fig. 4b, right panel; $r=0.93$, $P=0.0008)$, demonstrating that $\left[{ }^{18} \mathrm{~F}\right] 4 \mathrm{FN}$ accurately reported on the significant mouse-to-mouse heterogeneity of ROS burst in this model. Focused time activity curves (TACs), comparing uptake in the inflamed ankle to uptake in the vehicle-treated ankle (Fig. 4b, left panel), showed similar initial retention rates at very early time points (vascular phase), with large detectable differences starting at $17.5 \mathrm{~min}$ after injection $(P<0.0001)$, but the radioactivity reached a plateau in the inflamed ankle three times higher than in the normal ankle. Postmortem H\&E staining confirmed the expected edema and infiltration of innate immune cells in the inflamed ankle (Fig. $4 \mathrm{c}$, right panel) when compared to the non-inflamed ankle (Fig. 4c, left panel). Image-based whole-body bio-distribution kinetics also were calculated from the PET/CT images (Fig. 4d). Radioactivity was mainly cleared through the kidneys, as indicated by the initial renal influx and subsequent increase in radioactivity in the bladder over time. Modest hepatobiliary excretion was observed as well. The lower gastrointestinal tract showed the second highest activity, confirming that $\left[{ }^{18} \mathrm{~F}\right] 4 \mathrm{FN}$ displayed mixed renal and hepatobiliary clearance, with low muscle and bone retention. Retained radioactivity in the brain was low at $1 \mathrm{~h}$ after injection; however, the initial uptake of $5 \% \mathrm{ID} / \mathrm{cc}$ suggested that $\left[{ }^{18} \mathrm{~F}\right] 4 \mathrm{FN}$ might be capable of crossing an intact blood-brain barrier, with initial brain-to-heart ratios approaching 1 (Extended Data Fig. 2). 
Imaging contact dermatitis with $\left[{ }^{18} \mathrm{~F}\right] 4 \mathrm{FN}$ PET. $\left[{ }^{18} \mathrm{~F}\right] 4 \mathrm{FN}$ was tested in a model of mild contact dermatitis, known for recruitment of activated neutrophils ${ }^{24}$. One earlobe (right side) of immunocompetent mice (BALB/cN and C57Bl6/N strains) was treated topically with PMA to induce inflammation. The contralateral ear was treated with ethanol (vehicle control). After $1 \mathrm{~d}$, PMA-treated ears were erythematous by visual inspection (Extended Data Fig. 3b). One hour after injection of $\left[{ }^{18} \mathrm{~F}\right] 4 \mathrm{FN}$, the inflamed ear was clearly visualized on PET/CT scans (Fig. 5a and Extended Data Fig. 3a). MPO activity in the inflamed ear was confirmed by BLI with luminol immediately after PET imaging in a subset of mice (Extended Data Fig. 3c), cross-validating activation of the innate immune system.

To characterize the dependence of the PET signal on the route of administration, $\left[{ }^{18} \mathrm{~F}\right] 4 \mathrm{FN}$ was injected either i.p. or i.v. Both delivery routes yielded statistically detectable differences in standardized uptake value (SUV) between inflamed and vehicle-treated ears (Fig. 5b-d), strong contrast ratios and large Cohen's $d$ effect sizes. To test the robustness of the tracer to TH1 and $\mathrm{TH} 2$ strain differences, both $\mathrm{C} 57 \mathrm{Bl6} / \mathrm{N}$ and $\mathrm{BALB} / \mathrm{cN}$ mice, respectively, were tested. In both strains, retention of $\left[{ }^{18} \mathrm{~F}\right] 4 \mathrm{FN}$ within the inflamed ear was readily demonstrated, albeit $\mathrm{C} 57 \mathrm{Bl} / \mathrm{N}$ mice showed an overall higher retention (Fig. 5c). The target/off-target ratios for C57Bl6/N and $\mathrm{BALB} / \mathrm{cN}$ mice were $3.79 \pm 0.9$ and $2.30 \pm 0.89$, respectively. Contrast-to-noise ratios (mean on-target - mean off-target/s.d. off-target) were $5.2 \pm 1.7$ and $3.5 \pm 1.7$ for $\mathrm{C} 57 \mathrm{Bl} / \mathrm{N}$ and $\mathrm{BALB} / \mathrm{cN}$ mice, respectively.

Comparison with $\left[{ }^{18}\right.$ F]FDG, a clinically used PET agent. In the PMA model of inflammation, retention of $\left[{ }^{18} \mathrm{~F}\right] 4 \mathrm{FN}$ was compared to $\left[{ }^{18} \mathrm{~F}\right] \mathrm{FDG}$ PET, the most extensively used PET imaging tracer. $\left[{ }^{18} \mathrm{~F}\right] \mathrm{FDG}$ has been employed to assess inflammation with mixed results. When tested in the PMA model of mild contact dermatitis, $\left[{ }^{18} \mathrm{~F}\right]$ FDG occasionally showed slight asymmetry in regional retention (Fig. 5e) but was unable to quantitatively distinguish between inflamed and non-inflamed ears; quantitative $\mathrm{SUV}_{\mathrm{av}}$ values demonstrated only a $6 \%$ overall increase (Fig. $5 \mathrm{e}, \mathrm{f}$ ). Inflammation was confirmed both visually and through ear canal thickening on CT images. Although $\left[{ }^{18} \mathrm{~F}\right] \mathrm{FDG}$ retention trended in the expected direction, $\left[{ }^{18} \mathrm{~F}\right] 4 \mathrm{FN}$ showed striking superiority to $\left[{ }^{18} \mathrm{~F}\right] \mathrm{FDG}$ when compared by target/off-target ratios (4.3-fold for $\left[{ }^{18} \mathrm{~F}\right] 4 \mathrm{FN}$ versus 1.1 -fold for $\left[{ }^{18} \mathrm{~F}\right] \mathrm{FDG}$ retention; $P=0.04$ ) (Fig. $5 \mathrm{~g}$ ).

Fig. 4 | Imaging LPS-induced arthritis with $\left[{ }^{18} \mathrm{~F}\right]$ HFN PET. Image-derived TACs of an LPS model of arthritis demonstrated selective accumulation in inflamed ankles and correlated on a per-animal basis with the bioluminescence readout of inflammation (L-012). C57BI6/N mice were injected intra-articularly with LPS (left ankle; red circle) or vehicle (right ankle). After $24 \mathrm{~h}$, mild inflammation of the left ankle was confirmed by visual inspection. Dynamic PET/CT scans were acquired for $1 \mathrm{~h}$ after i.v. injection of $\left[{ }^{18} \mathrm{~F}\right] 4 \mathrm{FN}$. Mice were subsequently imaged, the same day, for RONS by BLI (L-012). a, Coronal [ $\left.{ }^{18} \mathrm{~F}\right] 4 \mathrm{FN}$ PET/CT image $1 \mathrm{~h}$ after injection (left) and BLI image (right). b, $\left[{ }^{18} \mathrm{~F}\right] 4 \mathrm{FN}$ TACs were quantified for LPS-treated and vehicle-treated ankles (left panel; $n=4$ each; $P<0.0001$, two-way ANOVA with subject matching in time and treatment repeated measures, time $\times$ treatment, two tailed), with large detectable differences starting at $17.5 \mathrm{~min}$ after injection $(P<0.0001$, two-way ANOVA with subject matching in time and treatment, post hoc test for difference at each time with Sidak correction for multiple comparisons; error bars = s.e.m.). $\left[{ }^{18} \mathrm{~F}\right] 4 \mathrm{FN}$ retention at $1 \mathrm{~h}$ directly correlated with $\mathrm{BLI}$ (right panel; $r=0.93$; $P=0.0008$, two-tailed test; each dot represents an individual ankle from last time point). c, H\&E staining cross-validated local infiltration/ inflammation (vehicle, left panel; LPS, right panel; same mouse as in a). d, Image-based bio-distribution of [ $\left.{ }^{18} \mathrm{~F}\right] 4 \mathrm{FN}$ over time was calculated from the dynamic PET/CT data, and \%ID/ $/ \mathrm{CC}_{\mathrm{av}}$ was plotted for various organs. Data are presented as mean values \pm s.e.m. Gl, gastrointestinal.

$\left[{ }^{18} \mathrm{~F}\right] 4 \mathrm{FN}$ retention in vivo depends upon Nox2. As $\left[{ }^{18} \mathrm{~F}\right] 4 \mathrm{FN}$ can be oxidized and retained in human neutrophil-like cells upon activation of MPO, the contribution in vivo of MPO to retention of $\left[{ }^{18} \mathrm{~F}\right] 4 \mathrm{FN}$ was investigated in mice by using MPO knockout mice $\left(\mathrm{Mpo}^{-/-}\right)$and by pharmacologically inhibiting peroxidases, including MPO, via blockade with 4-ABAH. In all rodent experiments performed, the $\mathrm{PMA} /$ vehicle ratios of $\left[{ }^{18} \mathrm{~F}\right] 4 \mathrm{FN}$ retention in wild-type (WT) versus $\mathrm{Mpo}^{-/-}$trended toward reduction but did not reach statistical significance (Fig. S4). We interpret these data to show that, at tracer level, the MPO contribution to $\left[{ }^{18} \mathrm{~F}\right] 4 \mathrm{FN}$ trapping in mice was less than $20 \%$, which was near the detection limit of the PET scanner. 4-ABAH treatment, at nearly the maximum

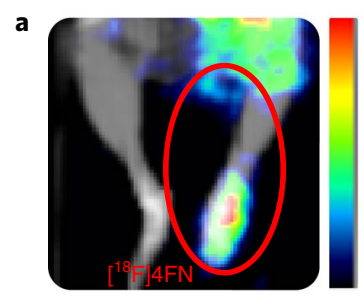

PET/CT $\left(\left[{ }^{18} \mathrm{~F}\right] 4 \mathrm{FN}\right)$

b

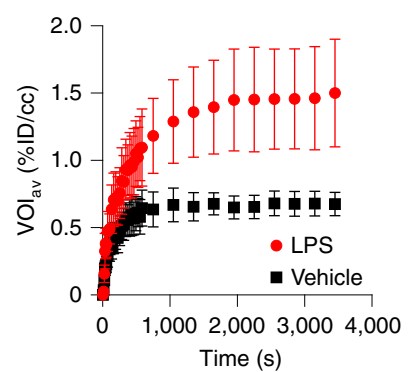

c
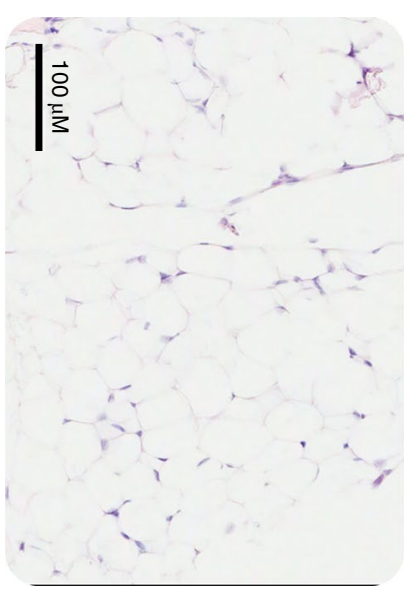

d

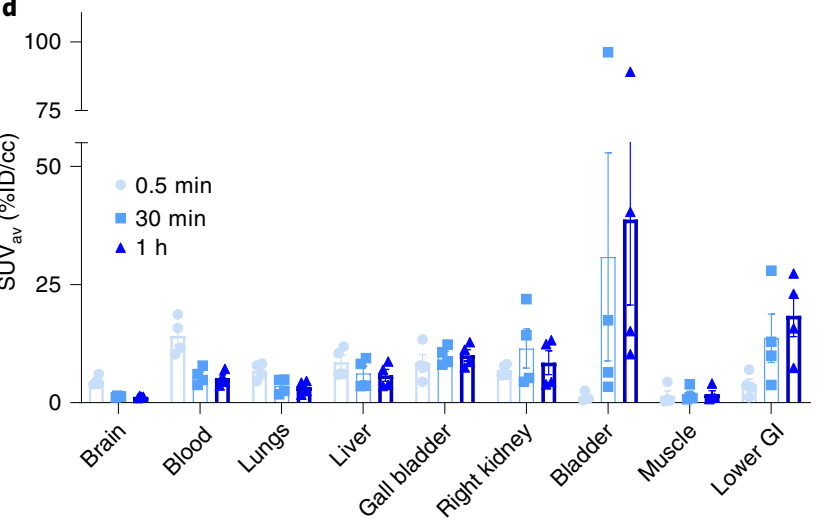



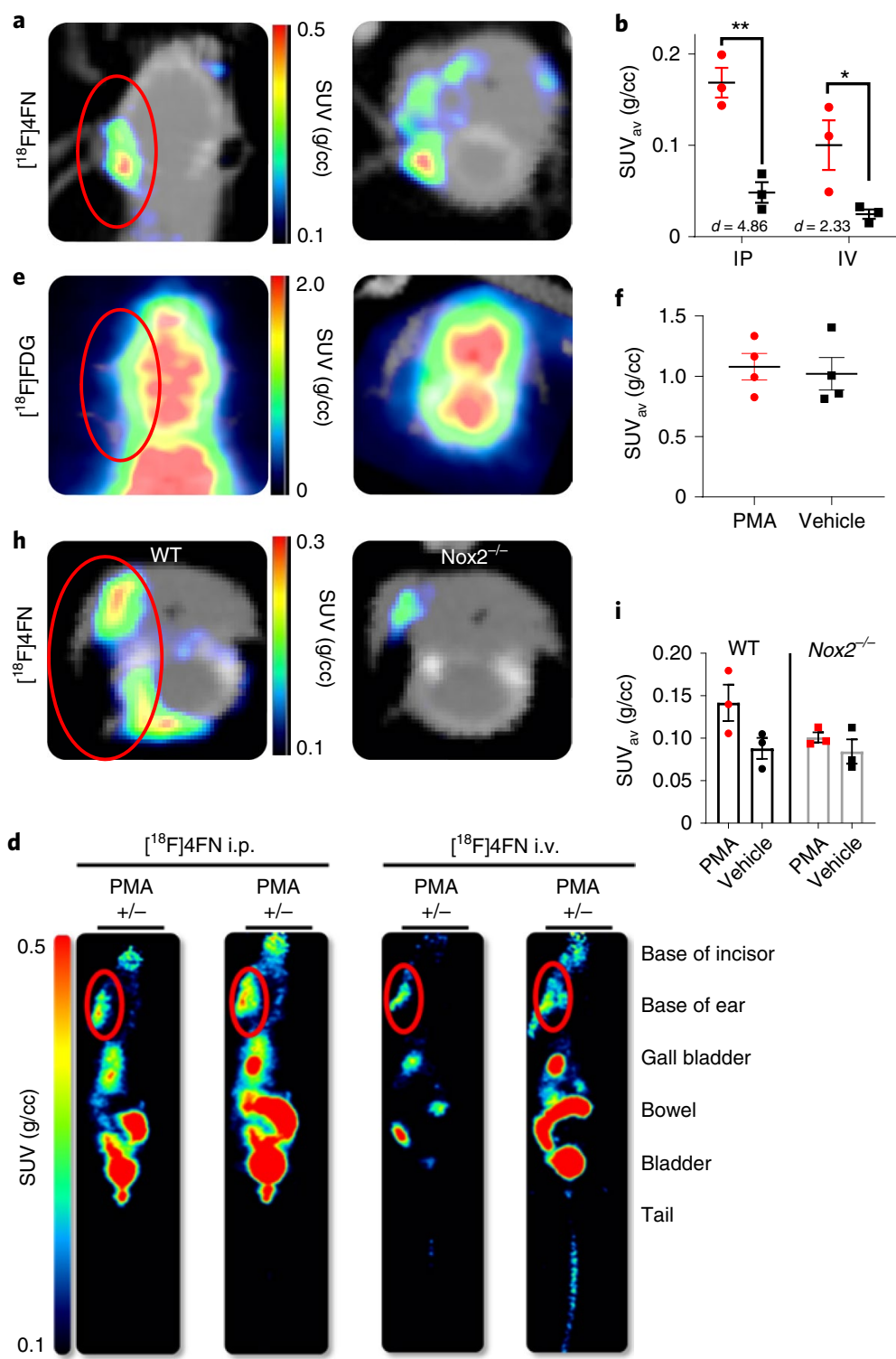

$\left[{ }^{18} \mathrm{~F}\right] 4 \mathrm{FN}$ i.p.
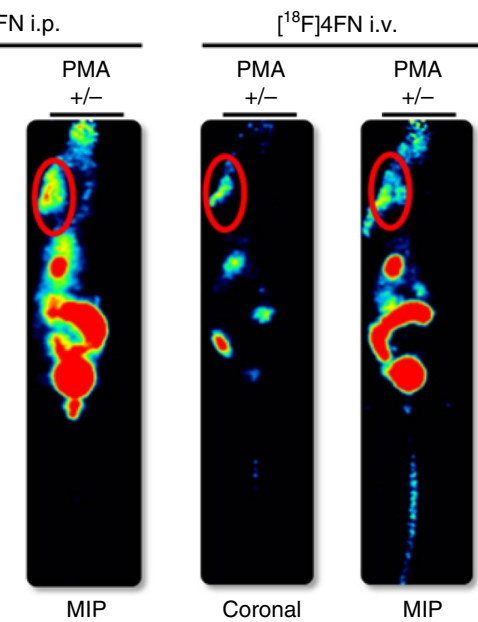

Base of incisor

Base of ear

Gall bladder

Bowel

Bladder

Tail

Fig. 5 | Imaging PMA-induced contact dermatitis with $\left[{ }^{18} \mathrm{~F}\right] 4 \mathrm{FN}$ PET. [18 $\left.\mathrm{F}\right] 4 \mathrm{FN}$ demonstrated robust retention in a model of mild contact dermatitis. Using female C57BI6/N (TH1-type) and BALB/CN (TH2-type) strains of mice, PMA was applied to the right ear (circled in red), and vehicle (ethanol) was applied to the contralateral left ear. Mice were weighed, injected with [ $\left.{ }^{18} \mathrm{~F}\right] 4 \mathrm{FN}$ either i.p. or i.v. and subsequently imaged by PET/CT at $1 \mathrm{~h}$ after injection. Volumes of interest were generated using CT image guidance, and boundaries were demarcated from PET data using a conservative 30\% maximum iso-contour. Red circles are provided for convenience to highlight PMA-induced ears. a, Coronal (left) and axial (right) plane [ $\left.{ }^{18} \mathrm{~F}\right] 4 \mathrm{FN}$ PET/CT images, respectively, of female Balb/cN 1h after injection, i.p. b, SUV ${ }_{a v}$ (g/cc) was quantified on a per-ear basis for C57BI6/N mice. Cohen's $d$ effect sizes were calculated. c, Two image metrics, target/non-target (T/NT) ratio and contrast-to-noise ratio (CNR), were calculated. d, Examples of whole-body $\left[{ }^{18} \mathrm{~F}\right] 4 \mathrm{FN}$ PET/CT coronal slices and maximum intensity projection (MIP) images illustrate both the uptake in the inflamed ear and primarily renal clearance route. $\mathbf{e}$, Coronal (left) and axial (right) plane $\left[{ }^{18} \mathrm{~F}\right] \mathrm{FDG}$ PET/CT images, respectively. A cohort of female C57BI6/N mice were treated with PMA and vehicle, injected with [ $\left.{ }^{18} \mathrm{~F}\right] \mathrm{FDG}$ i.v. and scanned at $1 \mathrm{~h}$ after injection, and PET/CT data were quantified as above. f, Inflammation was confirmed both visually and through ear canal thickening on $\mathrm{CT}$, but $\left[{ }^{18} \mathrm{~F}\right] \mathrm{FDG}$ PET/CT showed less than $15 \%$ difference between left and right ears. $\mathbf{g}$, T/NT ratios for $\left[{ }^{18} \mathrm{~F}\right] 4 \mathrm{FN}$ were quantitatively superior to $\left[{ }^{18} \mathrm{~F}\right]$ FDG; ${ }^{\star} P=0.04$, two-tailed t-test. h, Axial plane [ $\left.{ }^{18} \mathrm{~F}\right] 4 \mathrm{FN}$ PET/CT images of WT C57BI6/J (left) or Nox2 ${ }^{-/-}$(right) mice, respectively. i, SUV av values (g/ cc) for PMA-treated or vehicle-treated ears of WT C57BI6/J or Nox2-/- mice. j, Delta SUV av (PMA - vehicle) of WT C57BI6/J or Nox2-/- mice, indicating a significant reduction of PMA-induced $\left[{ }^{18} \mathrm{~F}\right] 4 \mathrm{FN}$ retention in Nox2-/- mice; $P=0.05$, two-tailed $t$-test. Data are presented as mean values \pm s.e.m.

deliverable dose, yielded $\sim 40 \%$ inhibition in BALB/cN mice treated with PMA in an independent cohort (Extended Data Fig. 4). The blunted MPO effects observed in mice were somewhat predictable given interspecies differences in ROS flux as measured by PMA-induced bioluminescence in cells, wherein orders of magnitude lower levels of ROS were observed in mice compared to humans (Extended Data Fig. 5).
As previously performed in cells (Fig. 2f), the contribution of Nox2 to retention of $\left[{ }^{18} \mathrm{~F}\right] 4 \mathrm{FN}$ in vivo was tested in the PMA-induced ear inflammation model by comparing WT and Cybb (Nox2) knockout $\left(\mathrm{Nox}^{-/-}\right)$mice (Fig. $5 \mathrm{H}$ ). In contrast to $\mathrm{Mpo}^{--}$, a $40 \%$

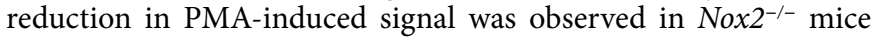
compared to WT (Fig. 5I). When expressed as the specific retention of $\left[{ }^{18} \mathrm{~F}\right] 4 \mathrm{FN}$ (PMA-vehicle $\left.(\Delta \mathrm{g} / \mathrm{cc})\right)$, calculated for each mouse, 
Nox $2^{-/-}$mice showed $71 \%$ less trapping of $\left[{ }^{18} \mathrm{~F}\right] 4 \mathrm{FN}$, demonstrating that Nox2-mediated RONS production was the main contributor to $\left[{ }^{18} \mathrm{~F}\right] 4 \mathrm{FN}$ accumulation in this murine contact dermatitis model (Fig. $5 \mathrm{j}$ ). The animal model was cross-validated by BLI using the RONS sensor L-012. Indeed, in PMA-treated Nox2 $2^{-/-}$mice, L-012 signal was reduced to close to the threshold of detection, similarly to

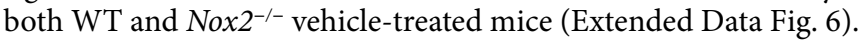

\section{Discussion}

Many inflammatory foci occur in deep organs or sites not amenable to biopsy or repetitive sampling, thus limiting access to vital information that could inform clinical decisions. Furthermore, peripheral assessment of circulating cytokines or other blood biomarkers might not accurately indicate the extent of local injury or inflammation and might be significantly diluted in the circulatory system or lose biological context. Conventional deep tissue tomographic imaging techniques, such as contrast-enhanced magnetic resonance imaging or $\mathrm{CT}$, can highlight areas of edema associated with inflammation but lack the specificity to differentiate non-inflammatory edema ${ }^{25}$. Molecular imaging with radiotracers has the advantage of enabling non-invasive, quantitative and repetitive analysis of the biochemical status of tissues and organs ${ }^{26}$, but standard clinical $\left[{ }^{18} \mathrm{~F}\right]$ FDG PET/CT, particularly in the context of imaging inflammatory foci, lacks sensitivity and diagnostic robustness. Critically, the mechanism of $\left[{ }^{18} \mathrm{~F}\right] \mathrm{FDG}$ retention via Glut-1/ hexokinase-I-mediated uptake and entrapment poorly correlates with respiratory burst ${ }^{27}$. Thus, it has been recognized that there is substantial unmet need for radiopharmaceuticals that identify and spatially-temporally localize focal inflammation based on the activation state of the innate immune system in vivo.

$\left[{ }^{18} \mathrm{~F}\right] 4 \mathrm{FN}$ is a novel radiopharmaceutical specifically developed for translational PET/CT imaging of ROS/RNS bursts, driven by activation of key peroxidases of the innate immune system, particularly MPO. Because innate immune cells reside constitutively in a resting state, but already primed with translated effector proteins lying in wait for stimulus-mediated activation, standard sequencing and immunohistochemistry data typically illuminate only cell localization, not activation. More advanced multiplexed cytometric methods or analysis of collateral damage by ROS/RNS must be employed to reveal the activation state of these cells. Moreover, the transient nature of ROS/RNS render them difficult to study ex vivo.

In this study, we developed $\left[{ }^{18} \mathrm{~F}\right] 4 \mathrm{FN}$ as a PET reporter of activated innate immunity that exploits the well-tuned redox potential of 1-naphthols, thereby providing selective reactivity and proximal binding of the radiopharmaceutical localized to activated innate immune cells. Several practical considerations were addressed to facilitate broad adoption of $\left[{ }^{18} \mathrm{~F}\right] 4 \mathrm{FN}$. First, a fully automated synthesis module provided a quick and efficient process compatible with the synthetic demands of short-half-life ${ }^{18} \mathrm{~F}$-labeled PET radiopharmaceuticals $(\sim 119 \mathrm{~min})$. Using the relatively new copper-mediated deboronation/fluorination of deactivated aryls, $\left[{ }^{18} \mathrm{~F}\right] 4 \mathrm{FN}$ was synthesized in good yields $(>5 \%$ from end of bombardment), high radiochemical purity (>99\%) and high molar activities (typically $>50 \mathrm{GBq}$ per $\mu \mathrm{mol}$, 'tracer' regimen). $\left[{ }^{18} \mathrm{~F}\right] 4 \mathrm{FN}$ showed a shelf-stability of at least $4 \mathrm{~h}$ and, in its final injectable formulation, did not require addition of stabilizers, a key feature that highlighted the 'goldilocks' uniqueness of $\left[{ }^{18} \mathrm{~F}\right] 4 \mathrm{FN}$ : stable enough to be synthesized, compounded, transported and injected but reactive enough to be responsive to high-energy RONS in vivo.

As described, a major contributor to the production of RONS by activation of the innate immune system is the NOX2/MPO axis. We wanted to demonstrate that this pathway was sufficient for oxidation of $\left[{ }^{18} \mathrm{~F}\right] 4 \mathrm{FN}$. As shown in Fig. 2, the contribution of supraphysiologic $\mathrm{H}_{2} \mathrm{O}_{2}(100 \mu \mathrm{M})$ alone to oxidation and retention of $\left[{ }^{18} \mathrm{~F}\right] 4 \mathrm{FN}$ was minimal, but the MPO-catalyzed oxidation was nearly total. We speculate that the relative kinetic stability of $\mathrm{H}_{2} \mathrm{O}_{2}$ and the low single-electron redox potential of $\mathrm{H}_{2} \mathrm{O}_{2}$ contributes to the low reactivity of $\left[{ }^{18} \mathrm{~F}\right] 4 \mathrm{FN}$ with $\mathrm{H}_{2} \mathrm{O}_{2}$. Notably, this analysis demonstrated that these oxidation processes yielded no significant $(<1 \%)$ defluorination of the parent compound. 'Neutrophil-like' differentiated HL-60 cells were selected for live cell analysis. Critically, as with neutrophils, PMA and LPS stimulate ROS in a NOX2- and MPO-dependent manner in differentiated HL-60 cells $^{28}$. In addition, HL-60 cells maintain undesired sources of potential tracer binding, including normal mitochondrial respiration, the LOX system, membrane-associated non-specific binding and PMA-induced macropinocytosis. In just $30 \mathrm{~min}$ of incubation with tracer levels of $\left[{ }^{18} \mathrm{~F}\right] 4 \mathrm{FN}$, five-fold retention levels over basal were measured after PMA stimulation. Broadly, this ratio suggested that the tracer might be useful for PET imaging in vivo, and that, in neutrophil-like cells, the retention of $\left[{ }^{18} \mathrm{~F}\right] 4 \mathrm{FN}$ was selective for an activated state. $\left[{ }^{18} \mathrm{~F}\right] 4 \mathrm{FN}$ binding also depended upon NOX2/ MPO. Blocking PMA-induced retention with DPI, a NOX2 and flavoprotein inhibitor, yielded more than 99\% inhibition of tracer trapping. The DPI data also indicated that PMA had not increased non-specific $\left[{ }^{18} \mathrm{~F}\right] 4 \mathrm{FN}$ uptake that could occur-for example, by PMA-stimulated micropinocytosis. The dependence upon MPO was tested by inhibition with the irreversible inhibitor 4-ABAH, which decreased retention of $\left[{ }^{18} \mathrm{~F}\right] 4 \mathrm{FN}$ to less than $5 \%$ of baseline, indicating that PMA-induced binding of $\left[{ }^{18} \mathrm{~F}\right] 4 \mathrm{FN}$ was mediated by MPO active site-derived oxidation/peroxidation reactions. Thus, in this model of human neutrophil-like cells, there was strong selectivity for the NOX2/MPO pathway versus non-specific binding, macropinocytosis or mitochondrial ROS.

Experiments in vivo yielded similar data. L-012 bioluminescence correlated strongly with $\left[{ }^{18} \mathrm{~F}\right] 4 \mathrm{FN}$ retention in an LPS model of arthritis. $\left[{ }^{18} \mathrm{~F}\right] 4 \mathrm{FN}$ retention was linearly correlated with photon flux from L-012, a validated inflammation RONS reporter. Histological cross-validation of the arthritis model demonstrated significant acute immune infiltration into the ankle and foot, confirming the anticipated Toll-like-receptor-induced focal infiltration. Because $\left[{ }^{18} \mathrm{~F}\right] 4 \mathrm{FN}$ retention correlated well with known BLI reporters of RONS in vivo, the casual dependence of trapping was further investigated. In a model of PMA-induced contact dermatitis, Nox $2^{-/-}$mice attenuated by $71 \%$ the retention of $\left[{ }^{18} \mathrm{~F}\right] 4 \mathrm{FN}$, despite physiological evidence of inflammation, such as thickening and erythema of the ears. This strongly suggested that the molecular mechanism of $\left[{ }^{18} \mathrm{~F}\right] 4 \mathrm{FN}$ retention was RONS-mediated redox reactions, rather than enhanced permeability and retention, also relevant to inflammation microenvironments. Unlike human neutrophil-like cells, in mice, $\left[{ }^{18} \mathrm{~F}\right] 4 \mathrm{FN}$ dependency upon MPO was smaller as characterized both by $\mathrm{Mpo}^{-/-}$mice and 4-ABAH inhibition. 4-ABAH inhibition yielded the largest decrease and indicated that, in the $\mathrm{Mpo}^{-/-}$mice, ROS flux was likely compensated by other pathways-for example, enhanced surface localization of NOX2 and increased superoxide anion production ${ }^{29}$. Nonetheless, we concluded that $\left[{ }^{18} \mathrm{~F}\right] 4 \mathrm{FN}$ was a marker of activated innate immunity in the three preclinical models of acute inflammation, each known to recruit high levels of activated neutrophils.

Potential adoption of a novel radiotracer into clinical practice demands significant superiority to $\left[{ }^{18} \mathrm{~F}\right] \mathrm{FDG}$, the gold standard of PET, which is used to image inflammation in selected settings by entirely different metabolic trapping mechanisms. In this study, we demonstrated superior retention of $\left[{ }^{18} \mathrm{~F}\right] 4 \mathrm{FN}$ ( five-fold over background) compared to $\left[{ }^{18} \mathrm{~F}\right] \mathrm{FDG}(\sim 1.1$-fold $)$ in vivo under appropriate conditions of ROS/RNS redox chemistry. Note that $\left[{ }^{18} \mathrm{~F}\right] 4 \mathrm{FN}$, a small molecule PET tracer, shares many practical characteristics of $\left[{ }^{18} \mathrm{~F}\right] \mathrm{FDG}$, including methods for automated synthesis, shelf stability, rapid renal excretion and robustness to route of injection, features that will assist clinical translation (Extended Data Table 2).

It is important to place this novel radiopharmaceutical in the context of existing PET tracers related to imaging innate immunity. 
Because reported models are generally different, direct quantitative comparisons are difficult, so evaluation is limited to qualitative impressions. For example, translocator protein (TSPO)-targeted tracers, such as $\left[{ }^{11} \mathrm{C}\right] \mathrm{PK}-11195$ and ${ }^{18} \mathrm{~F}-\mathrm{GE}-180$, that directly bind TSPO one to one, have been successfully used to monitor microglial activation in the brain of rodents ${ }^{30}$ but have faced severe challenges in peripheral rat models of inflammation, with maximum ratios of 1.3-fold over background and non-quantified contrast-to-noise ratios reported ${ }^{31}$. Moreover, whereas rodent myeloid cells underestimate ROS burst relative to human cells, suggesting that the $\left[{ }^{18} \mathrm{~F}\right] 4 \mathrm{FN}$ oxidation and trapping in humans could be stronger than those observed in preclinical models, conversely, rodents overestimate the role of TSPO activation, particularly in activated microg$\mathrm{lia}^{32}$, potentially restraining observable signal-to-noise in humans. Work continues in this area and might yet yield clinically actionable information ${ }^{33}$

Whereas TSPO activation occurs upstream of RONS production, other intriguing reporters relate to the downstream effect of RONS on cells. The glutamate analogue $5-\left[{ }^{18} \mathrm{~F}\right]$ fluoro-aminosuberic acid $\left(\left[{ }^{18} \mathrm{~F}\right] \mathrm{FASu}\right)^{34}$ leverages ATF4-mediated activation of the XCT transporter under conditions of oxidative stress ${ }^{35}$ and might provide useful information on immune system cells complementary to $\left[{ }^{18} \mathrm{~F}\right] 4 \mathrm{FN}$.

More closely related to $\left[{ }^{18} \mathrm{~F}\right] 4 \mathrm{FN}$ are molecules that have been synthesized to monitor activation of innate immunity via RONS activity. These can be broken into four classes based upon their core pharmacophore: luminol, dihydroethidium, ascorbate and hydroxyl-tryptophan. Ga-luminox ${ }^{36}$ is a luminol derivative that was tested under LPS-mediated stimulation of epithelial cell tumors and in a late whole-body toxic shock model. Although intriguing, no proof of ROS-mediated retention of the radiotracer was reported. Correlative fluorescence data suggested that the fluorescence signal was dependent upon mitochondria and iron-containing compounds. However, fluorescent probes can show different pharmacokinetic behaviors in vivo compared to similar radiotracers because of their structural differences and higher concentrations when injected into the body. ${ }^{18} \mathrm{~F}$-DHMT, based on dihydroethidium, has been synthesized via click chemistry and tested in models of cardiotoxicity ${ }^{37}$. In rodents, ${ }^{18} \mathrm{~F}$-DHMT shows a two-fold increase in retention in hearts of doxorubicin-treated mice versus control; however, in beagle dogs, baseline uptake is high, posing questions around the in vivo stability or selective activation of this PET tracer ${ }^{37}$. The redox potential of dihydroethidium $(0.1 \mathrm{~V})^{38}$ is below the single-electron redox potential of $\mathrm{H}_{2} \mathrm{O}_{2}$, indicating that $\mathrm{H}_{2} \mathrm{O}_{2}$ single-electron-mediated oxidation is possible and might explain the observed canine cardiac uptake. Such a background source would render innate immunity activation difficult to discern by ${ }^{18} \mathrm{~F}$-DHMT from high local metabolic fluxes of $\mathrm{H}_{2} \mathrm{O}_{2} \cdot{ }^{18} \mathrm{~F}$-ROS Trace was also published, leveraging a fluoroethyl group to label the pharmacophore ${ }^{39}$. A more recently published dihydroethidium analogue leverages direct aryl fluorination ${ }^{40}$ for imaging hydroxyl radical-mediated activation in the brain and might have the same context-dependent background issues discussed above but might be less susceptible to defluorination than ${ }^{18} \mathrm{~F}$-ROS Trace.

${ }^{11} \mathrm{C}-\mathrm{KS} 1$ (and, later, ${ }^{18} \mathrm{~F}-\mathrm{KS} 1$ ), an ascorbate analogue, has also been synthesized and proposed as an ROS sensor in tumor cells but has not been proposed for sensing activation of the innate immune system $^{41}$. Similarly to ethidium-based tracers, ascorbate has a standard redox potential of $0.3 \mathrm{~V}$, close to the single-electron redox potential of $\mathrm{H}_{2} \mathrm{O}_{2}$, which would lack selective reactivity to innate immune cell activation but might be advantageous for studying tumor-intrinsic ROS.

Another recent PET agent, ${ }^{18} \mathrm{~F}-\mathrm{MAPP}^{42}$, relies upon the MPO-mediated oxidation of the hydroxyl-tryptophan core to produce a signal. Although this molecule appears interesting, the compound requires anti-oxidant stabilizers in the formulation, even at preclinical doses, which might dampen desired signals in vivo, complicating applications and interpretation of data. Moreover, radiolysis might hinder radiochemical scalability of this compound. Nonetheless, ${ }^{18} \mathrm{~F}$-MAPP might provide additional preclinical orthogonal information relative to $\left[{ }^{18} \mathrm{~F}\right] 4 \mathrm{FN}$.

Although this study focused on the use of $\left[{ }^{18} \mathrm{~F}\right] 4 \mathrm{FN}$ to report on innate immune system activation, there are other circumstances wherein high-energy ROS are produced. $\left[{ }^{18} \mathrm{~F}\right] 4 \mathrm{FN}$ retention fundamentally involves the energy-weighted density (hence, high energy) of local RONS convolved with available reactive binding sites on local proteins and macromolecules. Thus, a possible scenario is the reaction of metal centers with $\mathrm{H}_{2} \mathrm{O}_{2}$ to generate high-energy hydroxyl radicals ${ }^{43}$. These conditions might include severe mitochondrial damage or ferroptosis ${ }^{44}$. Metal center reactions can also occur with very short lifetimes (nanoseconds) during external radiation therapy production of $\mathrm{H}_{2} \mathrm{O}_{2}$. These circumstances could certainly be discriminated by context or treatment.

The importance of these various mechanisms of host defense have been demonstrated through human, murine and pathogenintrinsic genetic and pharmacological interventions ${ }^{45}$. Although innate immunity is a first-line defense against microbial and viral infections, enduring unchecked respiratory burst contributes to a host of additional high-impact chronic and acute diseases, including non-alcoholic steatohepatitis, cancer, atherosclerosis and septic shock/cytokine storm ${ }^{46}$ and, of contemporaneous relevance, viral-induced multi-organ inflammation of COVID-19 (ref. ${ }^{47}$ ). Future applications for $\left[{ }^{18} \mathrm{~F}\right] 4 \mathrm{FN}$ PET might include prognostic or pharmacodynamic imaging of these diseases and therapy. Clinicians currently manage these patients locally blinded to the state of multi-focal disease, for which $\left[{ }^{18} \mathrm{~F}\right] 4 \mathrm{FN}$ PET might assist therapeutic decisions, including upstaging and triggers for aggressive treatment.

In conclusion, we described $\left[{ }^{18} \mathrm{~F}\right] 4 \mathrm{FN}$, a novel PET agent for imaging high-redox-potential RONS produced by the activated innate immune system. $\left[{ }^{18} \mathrm{~F}\right] 4 \mathrm{FN}$ could be reliably synthesized on an automated module and was able to report on the activation status of innate immune cells in cellulo and in vivo. $\left[{ }^{18} \mathrm{~F}\right] 4 \mathrm{FN}$ showed superiority to $\left[{ }^{18} \mathrm{~F}\right] \mathrm{FDG}$ and ${ }^{68} \mathrm{Ga}$-citrate in vivo, each representing conventional PET tracers used to image inflammation. $\left[{ }^{18} \mathrm{~F}\right] 4 \mathrm{FN}$ is trapped through a NOX2/MPO-dependent oxidation mechanism mediated by ROS/RNS, thus providing a mechanism-based signal selectively present during activation of innate immunity. The clinical utility of $\left[{ }^{18} \mathrm{~F}\right] 4 \mathrm{FN}$ will be characterized in pilot human studies that are now underway.

\section{Online content}

Any methods, additional references, Nature Research reporting summaries, source data, extended data, supplementary information, acknowledgements, peer review information; details of author contributions and competing interests; and statements of data and code availability are available at https://doi.org/10.1038/ s41587-021-01169-y.

Received: 9 November 2020; Accepted: 19 November 2021; Published online: 21 February 2022

\section{References}

1. Zindel, J. \& Kubes, P. DAMPs, PAMPs, and LAMPs in immunity and sterile inflammation. Annu. Rev. Pathol. 15, 493-518 (2020).

2. Schroder, K. \& Tschopp, J. The inflammasomes. Cell 140, 821-832 (2010).

3. Marquez, L. A. \& Dunford, H. B. Kinetics of oxidation of tyrosine and dityrosine by myeloperoxidase compounds I and II. Implications for lipoprotein peroxidation studies. J. Biol. Chem. 270, 30434-30440 (1995).

4. Nishinaka, Y., Arai, T., Adachi, S., Takaori-Kondo, A. \& Yamashita, K. Singlet oxygen is essential for neutrophil extracellular trap formation. Biochem. Biophys. Res. Commun. 413, 75-79 (2011).

5. Spiller, K. L. et al. Differential gene expression in human, murine, and cell line-derived macrophages upon polarization. Exp. Cell. Res. 347, 1-13 (2016). 
6. Montezano, A. C. \& Touyz, R. M. Reactive oxygen species and endothelial function-role of nitric oxide synthase uncoupling and Nox family nicotinamide adenine dinucleotide phosphate oxidases. Basic Clin. Pharmacol. Toxicol. 110, 87-94 (2012).

7. Arasimowicz-Jelonek, M., Floryszak-Wieczorek, J., Abramowski, D. \& Izbiańska, K. In: Nitric Oxide in Plants: Metabolism and Role in Stress Physiology (eds Khan, M. N., Mobin, M., Mohammad, F., \& Corpas, F. J.) 165-184 (Springer International Publishing, 2014).

8. Cronin, S. J. F., Woolf, C. J., Weiss, G. \& Penninger, J. M. The role of iron regulation in immunometabolism and immune-related disease. Front. Mol. Biosci. 6, 116 (2019).

9. Sharrock, J. \& Sun, J. C. Innate immunological memory: from plants to animals. Curr. Opin. Immunol. 62, 69-78 (2020).

10. Zámocký, M. et al. Independent evolution of four heme peroxidase superfamilies. Arch. Biochem. Biophys. 574, 108-119 (2015).

11. Davies, M. J. Myeloperoxidase-derived oxidation: mechanisms of biological damage and its prevention. J. Clin. Biochem. Nutr. 48, 8-19 (2011).

12. Jelcic, M., Enyedi, B., Xavier, J. B. \& Niethammer, P. Image-based measurement of $\mathrm{H}_{2} \mathrm{O}_{2}$ reaction-diffusion in wounded zebrafish larvae. Biophys. J. 112, 2011-2018 (2017).

13. Elias, J. M. A rapid, sensitive myeloperoxidase stain using 4-chloro1-naphthol. Am. J. Clin. Pathol. 73, 797-799 (1980).

14. Eastmond, D. A., French, R. C., Ross, D. \& Smith, M. T. Metabolic activation of 1-naphthol and phenol by a simple superoxide-generating system and human leukocytes. Chem. Biol. Interact. 63, 47-62 (1987).

15. Sreekanth, R., Prasanthkumar, K. P., Sunil Paul, M. M., Aravind, U. K. \& Aravindakumar, C. T. Oxidation reactions of 1- and 2-naphthols: an experimental and theoretical study. J. Phys. Chem. A 117, 11261-11270 (2013).

16. Islam, A., Lee, S.-E. \& Jang-Eok, K. Enhanced enzymatic transformation of 1-naphthol in the presence of catechol by peroxidase. J. Korean Soc. Appl. Biol. Chem. 57, 209-215 (2014).

17. Tredwell, M. et al. A general copper-mediated nucleophilic ${ }^{18} \mathrm{~F}$ fluorination of arenes. Angew. Chem. Int. Ed. Engl. 53, 7751-7755 (2014)

18. Daiber, A. et al. Measurement of NAD $(\mathrm{P}) \mathrm{H}$ oxidase-derived superoxide with the luminol analogue L-012. Free Radic. Biol. Med. 36, 101-111 (2004).

19. Xu, F., Koch, D. E., Kong, I. C., Hunter, R. P. \& Bhandari, A. Peroxidase-mediated oxidative coupling of 1-naphthol: characterization of polymerization products. Water Res. 39, 2358-2368 (2005).

20. Seitz, P. M. et al. Development of a high-throughput cell-based assay for superoxide production in HL-60 cells. J. Biomol. Screen. 15, 388-397 (2010)

21. Augsburger, F. et al. Pharmacological characterization of the seven human NOX isoforms and their inhibitors. Redox Biol. 26, 101272 (2019).

22. Doi, K., Leelahavanichkul, A., Yuen, P. S. \& Star, R. A. Animal models of sepsis and sepsis-induced kidney injury. J. Clin. Invest. 119, 2868-2878 (2009).

23. Cunningham, P. N., Wang, Y., Guo, R., He, G. \& Quigg, R. J. Role of Toll-like receptor 4 in endotoxin-induced acute renal failure. J. Immunol. 172, 2629-2635 (2004).

24. Gross, S. et al. Bioluminescence imaging of myeloperoxidase activity in vivo. Nat. Med. 15, 455-461 (2009).

25. Hayeri, M. R., Ziai, P., Shehata, M. L., Teytelboym, O. M. \& Huang, B. K. Soft-tissue infections and their imaging mimics: from cellulitis to necrotizing fasciitis. Radiographics 36, 1888-1910 (2016).

26. Galban, C. J. et al. Applications of molecular imaging. Prog. Mol. Biol. Transl. Sci. 95, 237-298 (2010).

27. Jones, H. A. et al. Dissociation between respiratory burst activity and deoxyglucose uptake in human neutrophil granulocytes: implications for interpretation of ${ }^{18}$ F-FDG PET images. J. Nucl. Med. 43, 652-657 (2002).

28. Bruno, J. G. \& Kiel, J. L. Luminol and diazoluminomelanin as indicators of HL-60 cell differentiation. Vitr. Cell Dev. Biol. Anim. 29A, 737-741 (1993).

29. Locksley, R. M., Wilson, C. B. \& Klebanoff, S. J. Increased respiratory burst in myeloperoxidase-deficient monocytes. Blood 62, 902-909 (1983).

30. Werry, E. L. et al. Recent developments in TSPO PET imaging as a biomarker of neuroinflammation in neurodegenerative disorders. Int. J. Mol. Sci. 20, 3161 (2019).

31. Shao, X. et al. Imaging of carrageenan-induced local inflammation and adjuvant-induced systemic arthritis with $\left[{ }^{11} \mathrm{C}\right]$ PBR28 PET. Nucl. Med. Biol. 40, 906-911 (2013).

32. Lee, Y., Park, Y., Nam, H., Lee, J. W. \& Yu, S. W. Translocator protein (TSPO): the new story of the old protein in neuroinflammation. BMB Rep. 53, 20-27 (2020).

33. Zhang, L. et al. Recent developments on PET radiotracers for TSPO and their applications in neuroimaging. Acta Pharm. Sin. B 11, 373-393 (2021).
34. Colovic, M. et al. Non-invasive use of positron emission tomography to monitor diethyl maleate and radiation-induced changes in system $\mathrm{x}_{\mathrm{C}}{ }^{-}$activity in breast cancer. Mol. Imaging Biol. 21, 1107-1116 (2019).

35 . Yang, H. et al. 18F-5-fluoroaminosuberic acid as a potential tracer to gauge oxidative stress in breast cancer models. J. Nucl. Med. 58, 367-373 (2017).

36. Sivapackiam, J. et al. Galuminox: preclinical validation of a novel PET tracer for non-invasive imaging of oxidative stress in vivo. Redox Biol. 37, 101690 (2020).

37. Wu, J. et al. Feasibility study of PET dynamic imaging of $\left[{ }^{18} \mathrm{~F}\right] \mathrm{DHMT}$ for quantification of reactive oxygen species in the myocardium of large animals J. Nucl. Cardiol. https://doi.org/10.1007/s12350-020-02184-3 (2020).

38. Wang, S. T. et al. Sensitivity of activatable reactive oxygen species probes by fluorescence spectroelectrochemistry. Analyst 138, 4363-4369 (2013).

39. Hou, C. et al. Development of a positron emission tomography radiotracer for imaging elevated levels of superoxide in neuroinflammation. ACS Chem. Neurosci. 9, 578-586 (2018)

40. Egami, H. et al. $\left[{ }^{18} \mathrm{~F}\right]$-Labeled dihydromethidine: positron emission tomography radiotracer for imaging of reactive oxygen species in intact brain. Org. Biomol. Chem. 18, 2387-2391 (2020).

41. Carroll, V. N. et al. $\left[{ }^{11} \mathrm{C}\right]$ Ascorbic and $\left[{ }^{11} \mathrm{C}\right]$ dehydroascorbic acid, an endogenous redox pair for sensing reactive oxygen species using positron emission tomography. Chem. Commun. (Camb.) 52, 4888-4890 (2016).

42. Wang, C. et al. An activatable PET imaging radioprobe is a dynamic reporter of myeloperoxidase activity in vivo. Proc. Natl Acad. Sci. USA 116, 11966-11971 (2019).

43. Halliwell, B. \& Gutteridge, J. M. Biologically relevant metal ion-dependent hydroxyl radical generation. An update. FEBS Lett. 307, 108-112 (1992).

44. Bhattacharjee, S., Chatterjee, S., Jiang, J., Sinha, B. K. \& Mason, R. P. Detection and imaging of the free radical DNA in cells-site-specific radical formation induced by Fenton chemistry and its repair in cellular DNA as seen by electron spin resonance, immuno-spin trapping and confocal microscopy. Nucleic Acids Res. 40, 5477-5486 (2012).

45. Leto, T. L. \& Geiszt, M. Role of Nox family NADPH oxidases in host defense. Antioxid. Redox Signal. 8, 1549-1561 (2006)

46. Kamada, N. \& Rogler, G. The innate immune system: a trigger for many chronic inflammatory intestinal diseases. Inflamm. Intest. Dis. 1, 70-77 (2016).

47. Tay, M. Z., Poh, C. M., Renia, L., MacAry, P. A. \& Ng, L. F. P. The trinity of COVID-19: immunity, inflammation and intervention. Nat. Rev. Immunol. 20, 363-374 (2020).

48. Wood, P. M. The potential diagram for oxygen at $\mathrm{pH}$ 7. Biochem. J. 253, 287-289 (1988)

49. Kucera, J. Biofouling of polyamide membranes: fouling mechanisms, current mitigation and cleaning strategies, and future prospects. Membranes (Basel) 9 111 (2019).

50. Koppenol, W. H., Moreno, J. J., Pryor, W. A., Ischiropoulos, H. \& Beckman, J. S. Peroxynitrite, a cloaked oxidant formed by nitric oxide and superoxide. Chem. Res. Toxicol. 5, 834-842 (1992).

51. Arnhold, J., Furtmuller, P. G. \& Obinger, C. Redox properties of myeloperoxidase. Redox Rep. 8, 179-186 (2003).

52. Koppenol, W. H., Stanbury, D. M. \& Bounds, P. L. Electrode potentials of partially reduced oxygen species, from dioxygen to water. Free Radic. Biol. Med. 49, 317-322 (2010).

53. Das, T. N. \& Neta, P. Reduction potentials of naphthoxyl and pyridoxyl radicals in aqueous solutions. J. Phys. Chem. A 102, 7081-7085 (1998).

54. Harvey, D. Standard reduction potentials by element. https://chem.libretexts. org/ (2021).

55. Koppenol, W. H. Thermodynamic considerations on the formation of reactive species from hypochlorite, superoxide and nitrogen monoxide. Could nitrosyl chloride be produced by neutrophils and macrophages? FEBS Lett. 347, 5-8 (1994).

56. Bartberger, M. D. et al. The reduction potential of nitric oxide (NO) and its importance to NO biochemistry. Proc. Natl Acad. Sci. USA 99, 10958-10963 (2002)

57. Halliwell, B., Clement, M. V. \& Long, L. H. Hydrogen peroxide in the human body. FEBS Lett. 486, 10-13 (2000).

58. Trujillo, M., Alvarez, B. \& Radi, R. One- and two-electron oxidation of thiols: mechanisms, kinetics and biological fates. Free Radic. Res. 50, 150-171 (2016).

Publisher's note Springer Nature remains neutral with regard to jurisdictional claims in published maps and institutional affiliations.

(c) The Author(s), under exclusive licence to Springer Nature America, Inc. 2022 


\section{Methods}

All experiments were conducted following the relevant ethical and safety guidelines. Studies were conducted under the supervision of the MD Anderson Institutional Animal Care and Use Committee (protocol no. 00001179). Radiation handling was conducted under the supervision of the MD Anderson Radiation Safety Committee (authorized user protocol 1446).

Reagents and instrumentation. Reagents and solvents were purchased from Thermo Fisher Scientific and Sigma-Aldrich, unless otherwise specified, and used without further purification. ${ }^{18} \mathrm{~F}$, as an aqueous solution, and $\left[{ }^{68} \mathrm{Ga}\right] \mathrm{GaCl}_{3}$ were purchased from MD Anderson's Center for Advanced Biomedical Imaging Cyclotron Radiochemical Facility (CRF). Radioactivity was measured using a dose calibrator (Capintec, CRC-15R). ${ }^{1} \mathrm{H}$ and ${ }^{13} \mathrm{C}$ NMR spectroscopy was performed at $\mathrm{MD}$ Anderson Cancer Center on a $500-\mathrm{MHz}$ or $600-\mathrm{MHz}$ spectrometer (Bruker) using tetramethylsilane as an internal reference. Mass spectronomy was performed at MD Anderson Cancer Center on a liquid chromatography mass spectrometer with an ACQUITY TQ Detector (Waters) using electrospray ionization.

Synthesis of precursor 2. Commercially available 4-(4,4,5,5-tetramethyl1,3,2-dioxaborolan-2-yl)naphthalen-1-ol (ChemBridge) $(\mathbf{1}, 100 \mathrm{mg}, 0.37 \mathrm{mmol})$ was dissolved in dichloromethane $(1.5 \mathrm{ml})$, and $\mathrm{Boc}_{2} \mathrm{O}(81 \mathrm{mg}, 0.37 \mathrm{mmol})$ and DMAP ( $45 \mathrm{mg}, 0.37 \mathrm{mmol}$ ) were added in turn. The mixture was stirred at room temperature overnight; the solvent was removed; and the crude residue was purified on silica gel (Biotage, \% AcOEt in hexanes: $0 \%$ for $4 \mathrm{cv}, 0 \% \rightarrow 20 \%$ in $5 \mathrm{cv}$, $20 \%$ for $2 \mathrm{cv})$. Protected naphthol $2(110 \mathrm{mg})$ was obtained as a white solid in $80 \%$ yield (Extended Data Fig. 1).

2: ${ }^{1} \mathrm{H}$ NMR $(500 \mathrm{MHz}$, chloroform- $d) \delta 8.84-8.76(\mathrm{~m}, 1 \mathrm{H}), 8.08(\mathrm{~d}, J=7.6 \mathrm{~Hz}$, $1 \mathrm{H}), 8.00(\mathrm{dt}, J=8.1,1.0 \mathrm{~Hz}, 1 \mathrm{H}), 7.58-7.49(\mathrm{~m}, 2 \mathrm{H}), 7.32(\mathrm{~d}, J=7.6 \mathrm{~Hz}, 1 \mathrm{H}), 1.58$ (s, 9H), $1.41(\mathrm{~s}, 12 \mathrm{H}) \cdot{ }^{13} \mathrm{C} \mathrm{NMR}\left(126 \mathrm{MHz}, \mathrm{CDCl}_{3}\right) \delta 151.6(\mathrm{~s}), 149.6(\mathrm{~s}), 138.4(\mathrm{~s})$, $135.6(\mathrm{~d}), 128.6$ (d), 126.9 (d), 126.6 (d), 126.0 (s), 121.2 (d), 116.9 (d), 83.8 (s), 83.7 (s), 81.0 (s), 27.8 (q, 3C), 24.9 (q, 4 C). MS (ESI) $\mathrm{m} / z$ (\% relative intensity) 271 (80), $393[\mathrm{M}+\mathrm{Na}]^{+}(40)$.

Synthesis of $\left[{ }^{18} \mathbf{F}\right]$ FFN. Radiosynthesis of $\left[{ }^{18} \mathrm{~F}\right] 4 \mathrm{FN}$ was performed on a TRACERlab FX FN automatic module (GE Healthcare). Aqueous $\left[{ }^{18} \mathrm{~F}\right]$ fluoride was adsorbed on an ion exchange cartridge (pre-conditioned Sep-PAK Light QMA Cartridge, $\mathrm{ABX}) .\left[{ }^{18} \mathrm{~F}\right]$ Fluoride was flushed into the reaction vial with a potassium carbonate and Kryptofix 222 water $/ \mathrm{CH}_{3} \mathrm{CN}$ solution $\left(700 \mu \mathrm{l} ; 52.8 \mathrm{mg}\right.$ of $\mathrm{K}_{2} \mathrm{CO}_{3}$, $240.1 \mathrm{mg}$ of $\mathrm{K}_{222}, 4 \mathrm{ml}$ of water, $16 \mathrm{ml}$ of $\left.\mathrm{CH}_{3} \mathrm{CN}\right)$. The solution was dried under vacuum and nitrogen flow at $60^{\circ} \mathrm{C}$ for $2 \mathrm{~min}$. Dry $\mathrm{CH}_{3} \mathrm{CN}(500 \mu \mathrm{l})$ was added, and the mixture was azeotropically dried at $120^{\circ} \mathrm{C}$ for an additional $3 \mathrm{~min}$. Synthesis of $4-\left[{ }^{18} \mathrm{~F}\right]$ fluoro-1-naphthol was carried out by adding Boc naphthol boronate $2(7 \mathrm{mg})$ and $\mathrm{CuOTf}_{2}(\mathrm{Py})_{4}(15 \mathrm{mg}$, Sigma-Aldrich) in dry DMF $(600 \mu \mathrm{l})$ to the dried $\left[{ }^{18} \mathrm{~F}\right]$ fluoride. The mixture was stirred at $110^{\circ} \mathrm{C}$ for $20 \mathrm{~min}$ and cooled down to $80^{\circ} \mathrm{C}$, and $\mathrm{HCl} 1 \mathrm{M}(1 \mathrm{ml})$ was added. The mixture was stirred at $80^{\circ} \mathrm{C}$ for $10 \mathrm{~min}$, cooled down to $30^{\circ} \mathrm{C}$ and diluted with water $(3 \mathrm{ml})$. Crude was purified by semi-preparative HPLC (Luna 5- $\mathrm{mm} \mathrm{C18(2)} \mathrm{column,} 100 \AA$, $250 \times 10 \mathrm{~mm})$ eluting with a $50 \% \mathrm{MeCN} /$ water $\left(0.085 \% \mathrm{H}_{3} \mathrm{PO}_{4}\right)$ mobile phase (room temperature, $15 \mathrm{~min}$ ). Radioactive product was collected into the TRACERlab collection flask pre-filled with water $(50 \mathrm{ml})$. Solution was loaded onto two in-series tC2 cartridges (Sep-PAK, Waters). Cartridges were washed with $6 \mathrm{ml}$ of water, dried under nitrogen and eluted with ethanol. The overall synthesis time was approximately $70 \mathrm{~min}$. Activity was determined with a dose calibrator (Capintec, Mirion Technology), and a sample was taken for quality control. Quality control was performed by analytical radio-HPLC (Agilent 1260 Infinity II) using a Waters XBridge C18 column $(3.5 \mu \mathrm{m}, 4.6 \times 250 \mathrm{~mm}$; Method: A-water (0.1\% TFA), B-MeCN (0.1\% TFA) B: $40 \%$ for $3 \mathrm{~min}, 40-95 \%$ in $7 \mathrm{~min}, 95 \%$ for $1 \mathrm{~min}$, flow $1 \mathrm{ml}$ $\left.\mathrm{min}^{-1}\right)$. The identity of the radiolabeled compound was confirmed by co-elution with 4-fluoro-1-naphthol (Toronto Research Chemicals) (Extended Data Fig. 1).

$\left[{ }^{18} \mathrm{~F}\right] 4 \mathrm{FN}$ stability testing. For shelf stability, $\left[{ }^{18} \mathrm{~F}\right] 4 \mathrm{FN}$, in its final formulation of $10 \%$ ethanol/PBS, was tested for stability every hour, up to $4 \mathrm{~h}$ after formulation. $\left[{ }^{18} \mathrm{~F}\right] 4 \mathrm{FN}$ was maintained in an open-air, non-inert environment during the testing period. For plasma stability, $\left[{ }^{18} \mathrm{~F}\right] 4 \mathrm{FN}$ was incubated in mouse plasma at $37^{\circ} \mathrm{C}$ for $1 \mathrm{~h}$. Samples were analyzed by analytical radio-HPLC (Agilent 1260 Infinity II) using a Waters XBridge C18 column $(3.5 \mu \mathrm{m}, 4.6 \times 250 \mathrm{~mm}$; Method: A-water ( $0.1 \%$ TFA), B-MeCN (0.1\% TFA), B: $40 \%$ for $3 \mathrm{~min}, 40-95 \%$ in $7 \mathrm{~min}, 95 \%$ for $1 \mathrm{~min}$, flow $\left.1 \mathrm{ml} \mathrm{min}^{-1}\right)$.

Synthesis of ${ }^{68} \mathrm{Ga}$-citrate and $\left[{ }^{18} \mathrm{~F}\right] \mathrm{FDG} .{ }^{68} \mathrm{Ga}$-citrate was synthesized following a literature procedure ${ }^{59} \cdot\left[{ }^{18} \mathrm{~F}\right] \mathrm{FDG}$ was obtained from the CRF

In vitro enzyme assays. In 1.5 - $\mathrm{ml}$ autoclaved plastic tubes (Eppendorf), $\left[{ }^{18} \mathrm{~F}\right] 4 \mathrm{FN}$ was incubated with $0.2 \mu \mathrm{g}$ of recombinant human MPO (Millipore), $\mathrm{H}_{2} \mathrm{O}_{2}(100 \mu \mathrm{M})$ or both in $100 \mu \mathrm{M}$ PBS (Sigma-Aldrich). $\left[{ }^{18} \mathrm{~F}\right] 4 \mathrm{FN}$ was incubated at $37^{\circ} \mathrm{C}$ for $1 \mathrm{~h}$. Reactions were quenched with $100 \mu \mathrm{l}$ of ice-cold ethanol and maintained on ice until radio-HPLC analysis. In parallel, $100 \mu \mathrm{M}$ L-012 (Wako) was reacted with the same reagents on the same day in black-walled 96-well plates (Corning) to validate activity and specificity.
In cellulo radiotracer assays. Human HL-60 acute promyelocytic leukemia cells (American Type Culture Collection, CCL-240) were cultured in IMDM with 20\% FBS. The HL-60 cells were differentiated into a neutrophil-like phenotype by incubation with $1 \mu \mathrm{M}$ all-trans retinoic acid (Sigma-Aldrich) in culture medium for $3 \mathrm{~d}$ before the assay. Cells were transferred from culture medium to $0.6-\mathrm{ml}$ tubes containing 1 million cells in $0.5 \mathrm{ml}$ of MEBSS with $1 \%$ bovine calf serum on the day of the assay. The tubes were incubated at $37^{\circ} \mathrm{C}$ for $1 \mathrm{~h}$. Next, $20 \mu \mathrm{M}$ 4-ABAH (Cayman Chemical), $10 \mu \mathrm{M}$ diphenyleneiodonium chloride (Selleck Chemicals) or vehicle was added to the tubes, which were allowed to incubate for $30 \mathrm{~min}$ at $37^{\circ} \mathrm{C}$. The cells were then activated with $1 \mu \mathrm{M}$ PMA (Sigma-Aldrich) or treated with vehicle and incubated for an additional $30 \mathrm{~min}$ at $37^{\circ} \mathrm{C}$. All tubes were then incubated with $0.169 \pm 0.007 \mu \mathrm{Ci}$ of $\left[{ }^{18} \mathrm{~F}\right] 4 \mathrm{FN}$ for $30 \mathrm{~min}$ at $37^{\circ} \mathrm{C}$ to allow cell uptake and retention. Tracer retention was stopped by adding $25 \mu \mathrm{l}$ of $6.1 \mathrm{~N}$ trichloroacetic acid to the tubes on ice. The cells were centrifuged at 1,200 r.p.m. for $3 \mathrm{~min}$ at $4^{\circ} \mathrm{C}$, and the extracellular space was sampled for activity counting. Cell pellets were washed with ice-cold MEBSS containing $1 \%$ bovine calf serum and re-suspended in new tubes before centrifuging and washing again. Sodium borate buffer $(10 \mathrm{mM})$ containing $1 \%$ SDS was added to cell pellets to allow lysis at room temperature for $30 \mathrm{~min}$. Cell lysates were sampled for activity counting, and the remaining lysate was allowed to decay before a BCA assay to obtain protein concentration. Cell-associated and extracellular counts were obtained using a gamma counter (2480 WIZARD2 Automatic, PerkinElmer). Data were quantified as the ratio of cell-associated counts per milligram of protein over concentration of radiotracer in the extracellular space.

PET/CT imaging and analysis. For $\left[{ }^{18} \mathrm{~F}\right] \mathrm{FDG}$ PET/CT imaging experiments, mice were fasted for more than $4 \mathrm{~h}$ before injection. Mice were injected i.v. under light anesthesia with $\left[{ }^{18} \mathrm{~F}\right] \mathrm{FDG}$ (obtained from the CRF at MD Anderson) and then allowed to awaken, move and drink water ad libitum. Similarly, but without fasting, mice were injected i.v. (unless noted) with $\left[{ }^{18} \mathrm{~F}\right] 4 \mathrm{FN}$. Cages were kept on a cage warmer during tracer distribution and washout periods. Mice were scanned at the indicated times after injection with a 10-min PET/CT acquisition (Albira, Bruker) using a 15-cm field of view (FOV); CT images were acquired for fusion using a $7-\mathrm{cm}$ FOV, stepped and stitched if required. PET reconstruction was by MLEM 3D, 12 iterations, with decay, random and scatter correction applied to $500-\mu \mathrm{m}$ isotropic voxels. CT is reconstructed with filtered back projection and $500-\mu \mathrm{m}$ isotropic voxels. The preclinical PET system at the MD Anderson Small Animal Imaging Facility includes daily quality control with flood phantoms as well as at least one annual preventive maintenance, including quantitative calibration. Actual injected dose was calculated based on measuring the pre- and post-injection activity in the syringe with a dose calibrator (Capintec), and mice were individually weighed for static images. Image data were decay-corrected to injection time (Albira, Bruker) and corrected for individual injected dose (\%ID/cc) and, where indicted, normalized to animal weight, expressed as SUV (g/cc) (PMOD, PMOD Technologies). For dynamic images, mice were injected on the imaging system, and $\% \mathrm{ID} / \mathrm{cc}$ was calculated on a per-mouse basis from the image-derived whole mouse activity.

Inflammation models in vivo. Whole-body inflammation was induced in female C57B16/N mice with LPS (Escherichia coli 055:B5 Ultrapure, InvivoGen) injection, $20 \mathrm{mg} \mathrm{kg}^{-1}$ i.p., and compared to saline control. Four hours later, mice were imaged with $\left[{ }^{18} \mathrm{~F}\right] 4 \mathrm{FN}$ or ${ }^{68} \mathrm{Ga}$-citrate as above and euthanized before onset of major symptoms.

Acute arthritis was induced with intra-articular LPS $(20 \mu \mathrm{g}$ in $20 \mu \mathrm{l}$ of saline) into female $\mathrm{C} 57 \mathrm{Bl6} / \mathrm{N}$ (Taconic) mice; saline injection served as a control. Twenty-four hours later, mice with visibly inflamed ankles were injected with $\left[{ }^{18} \mathrm{~F}\right] 4 \mathrm{FN}$ i.v. and scanned continuously for $1 \mathrm{~h}$ with PET in list mode. Images were reconstructed, and PET/CT TACs were quantified. On the same day, mice were injected with L-012 sodium salt in saline $\left(20 \mathrm{mg} \mathrm{kg}^{-1}\right.$ i.p.) and imaged in bioluminescence and reflectance mode $10 \mathrm{~min}$ after injection on a bioluminescence/X-ray imaging system (Xtreme, Bruker). Images were acquired with a $19-\mathrm{cm}$ FOV, f/1.1, binning $4 \times 4,243 \mathrm{~s}$ or $4 \mathrm{~min}$. Mice were then euthanized, and ankles were harvested, fixed, decalcified and stained with $\mathrm{H} \& \mathrm{E}$ (Histochemistry Core, MD Anderson).

To induce acute contact dermatitis, adult female C57Bl6/N mice (Taconic) or female BALB/cN mice (BALB/cAnNTac, Taconic) (20-30 weeks old) were topically treated with PMA (Sigma-Aldrich, $400 \mu \mathrm{M}$, ethanol) on the right ear or vehicle (ethanol) on the left ear. Twenty-four hours later, mice were injected with $\left[{ }^{18} \mathrm{~F}\right] 4 \mathrm{FN}$ or $\left[{ }^{18} \mathrm{~F}\right] \mathrm{FDG}$ as indicated and imaged.

Female $\mathrm{Cybb}^{-/-}$mice (also known as $\mathrm{Nox}^{-/-}$) and $\mathrm{Mpo}^{-/-}$mice were obtained from Jackson Laboratories and compared to strain- and age-matched C57Bl6/J mice, also from Jackson Laboratories.

Reporting Summary. Further information on research design is available in the Nature Research Reporting Summary linked to this article.

\section{Data availability}

Source data are provided with this paper. Any remaining raw data will be available from the corresponding author upon reasonable request. Source data are provided with this paper. 


\section{References}

59. Jensen, S. B., Nielsen, K. M., Mewis, D. \& Kaufmann, J. Fast and simple one-step preparation of ${ }^{68} \mathrm{Ga}$ citrate for routine clinical PET. Nucl. Med. Commun. 34, 806-812 (2013).

\section{Acknowledgements}

We acknowledge support from the Gerald Dewey Dodd, Jr. Endowed Distinguished Chair at The University of Texas MD Anderson Cancer Center and a Faculty UT STARs Award. We would like to thank the Small Animal Imaging Facility and the Science Park Research Histology, Pathology and Imaging Core at MD Anderson Cancer Center for animal imaging and histology, respectively, especially C. Kingsley and J. DeLacerda. Both core facilities obtain support from the National Cancer Institute Cancer Center Support Grant (P30 CA016672).

\section{Author contributions}

Conceptualization: F.P., S.T.G. and D.P.W.; Methodology: F.P. and S.T.G.; Experimental performance: F.P., S.T.G., S.Q. and V.P.; Formal analysis: F.P., S.T.G., S.Q., V.P. and D.P.W.; Writing—original draft preparation: F.P., S.T.G. and D.P.W.; Writing—review and editing:
F.P., S.T.G., S.Q., V.P. and D.P.W.; Funding acquisition: D.P.W. All authors have read and agreed to the published version of the manuscript.

\section{Competing interests}

The University of Texas MD Anderson Cancer Center has filed a patent application on compounds and methods described in this report (S.T.G., F.P. and D.P.W., inventors). The remaining authors have no conflicts of interest.

\section{Additional information}

Extended data is available for this paper at https://doi.org/10.1038/s41587-021-01169-y. Supplementary information The online version contains supplementary material available at https://doi.org/10.1038/s41587-021-01169-y.

Correspondence and requests for materials should be addressed to David Piwnica-Worms.

Peer review information Nature Biotechnology thanks Delphine Chen, Xiaoyuan Chen and Kenneth Krohn for their contribution to the peer review of this work.

Reprints and permissions information is available at www.nature.com/reprints. 


\section{${ }^{1}$ H NMR (2):}

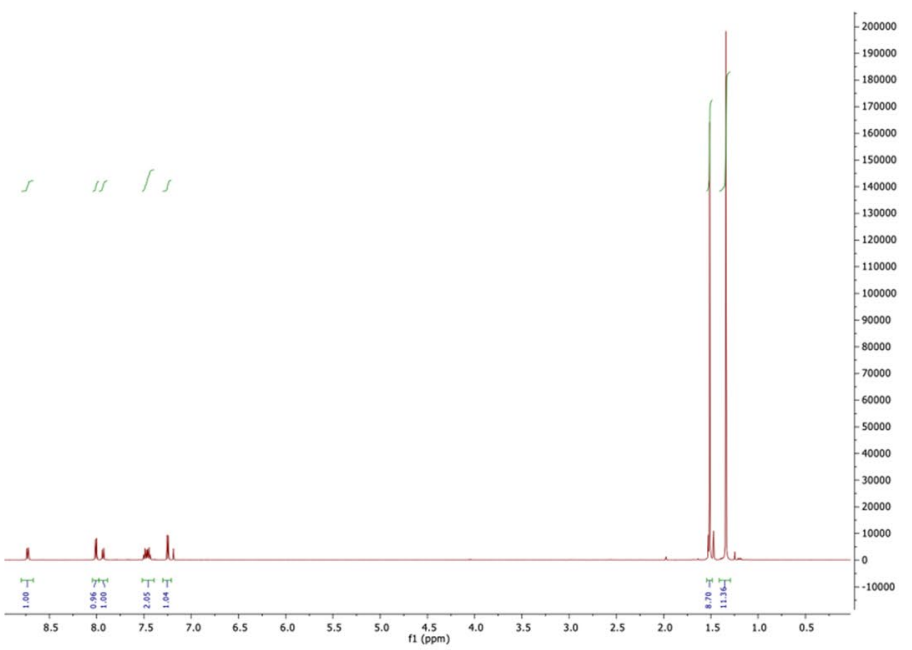

${ }^{13}$ C NMR (2):

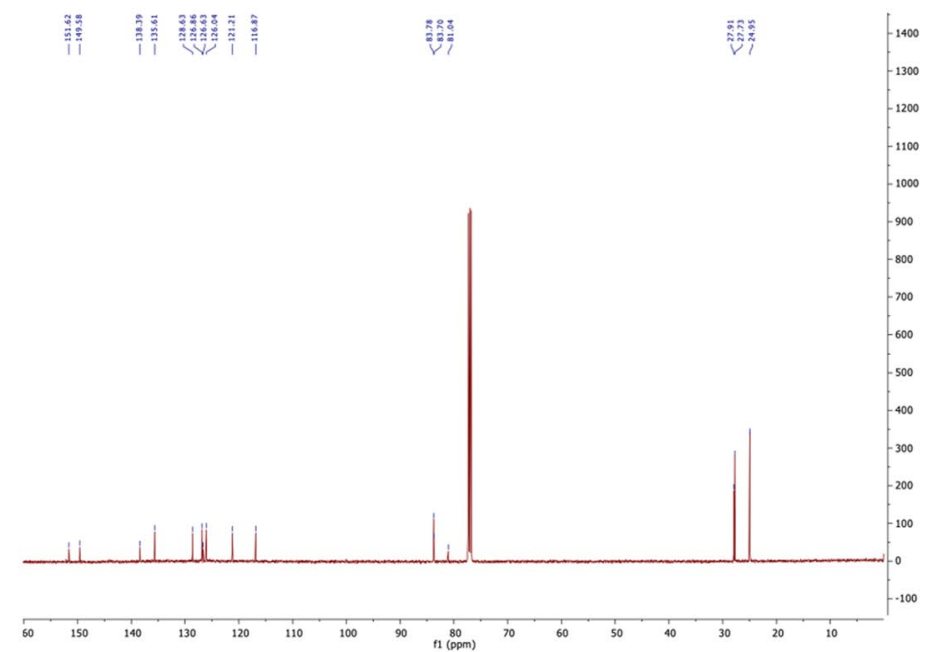

\section{HPLC analysis of $\left[{ }^{18} \mathrm{~F}\right] 4 \mathrm{FN}$ :}

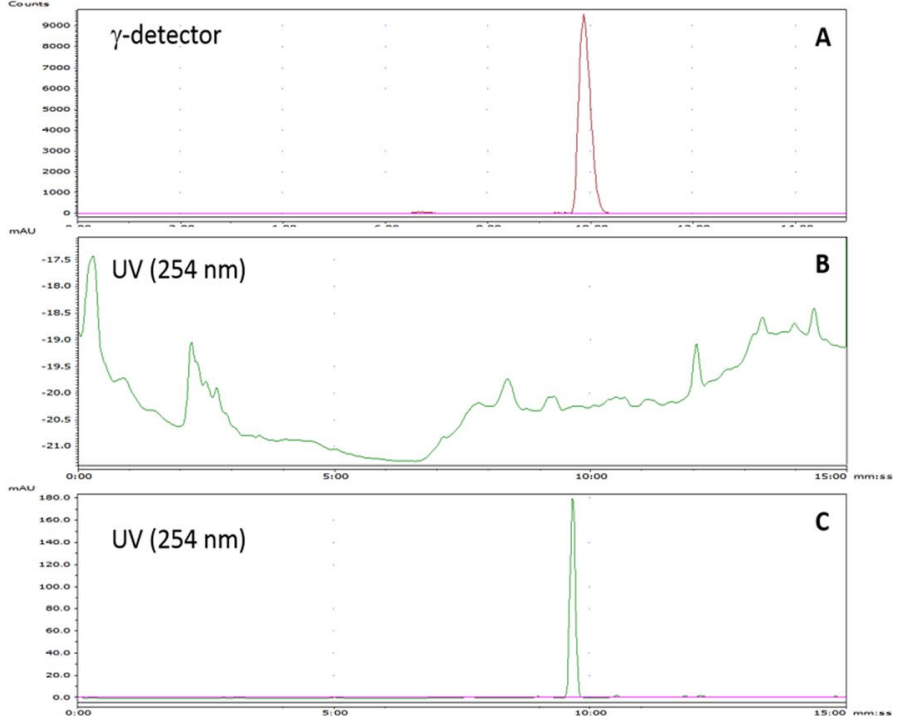


Extended Data Fig. 1 | Chemical characterization. ${ }^{1} \mathrm{H}$ NMR (compound 2), top; ${ }^{13} \mathrm{C} N M R$ (compound 2), mid; HPLC analysis of [ $\left.{ }^{18} \mathrm{~F}\right] 4 \mathrm{FN}$, bottom, A: QC of radioactive $\left[{ }^{18} \mathrm{~F}\right] 4 \mathrm{FN}$ (gamma trace). B: QC of radioactive $\left[{ }^{18} \mathrm{~F}\right] 4 \mathrm{FN}$ (UV trace at $254 \mathrm{~nm}$ ). C: cold $4 \mathrm{FN}$ as reference compound. HPLC column: Bridge C18, $3.5 \mu \mathrm{m}, 4.6 \times 250 \mathrm{~mm}$; Method: A-water (0.1\% TFA), B-MeCN (0.1\% TFA) B: $40 \%$ for $3 \mathrm{~min}, 40 \% \rightarrow 95 \%$ in $7 \mathrm{~min}, 95 \%$ for $1 \mathrm{~min}$, flow $1 \mathrm{~mL} / \mathrm{min}$. NOTE the compressed scale of $B$ to highlight the high purity of and molar activity of the compound. 

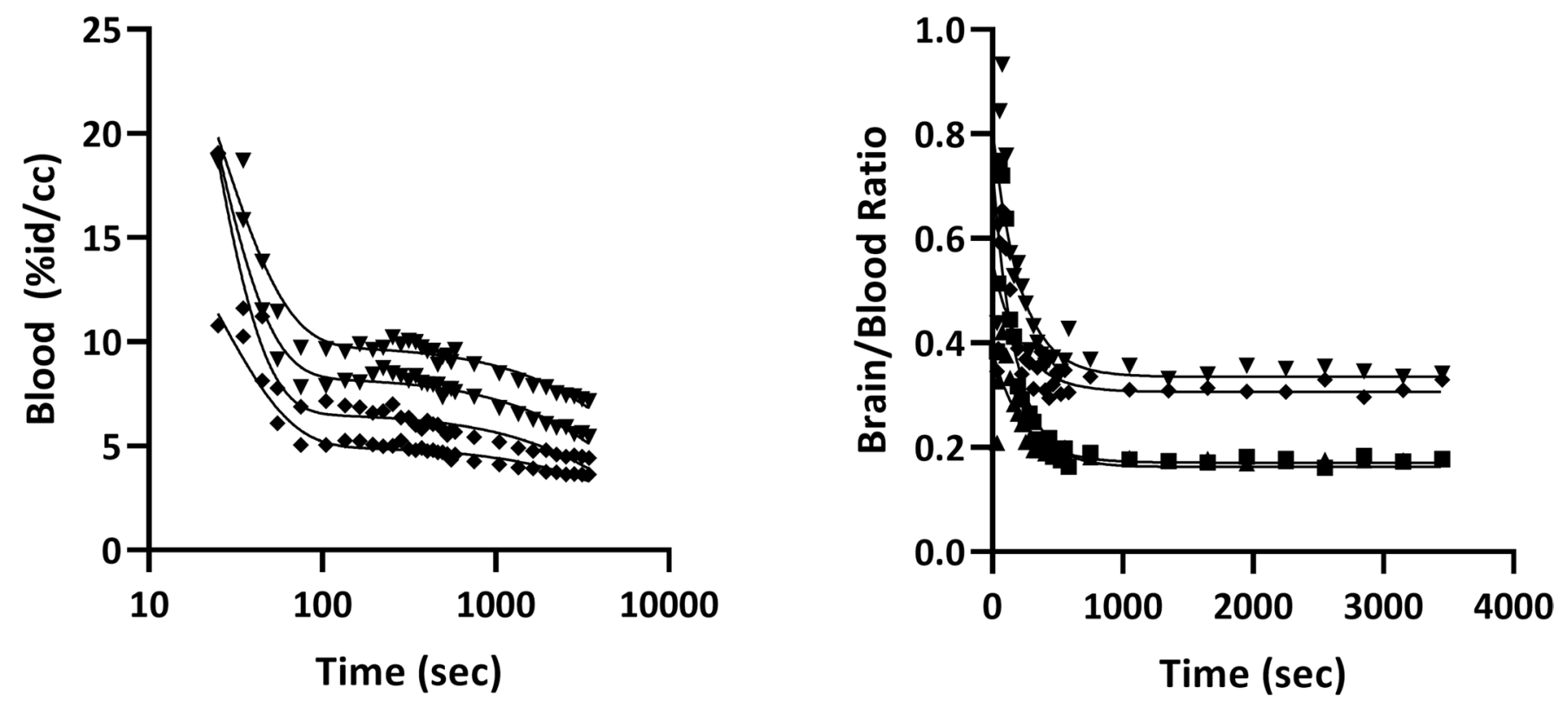

Extended Data Fig. 2 | PET image-based clearance and blood-to-brain ratios. Individual PET image-based time-activity curves derived from heart (representing the blood pool) and brain VOls. 


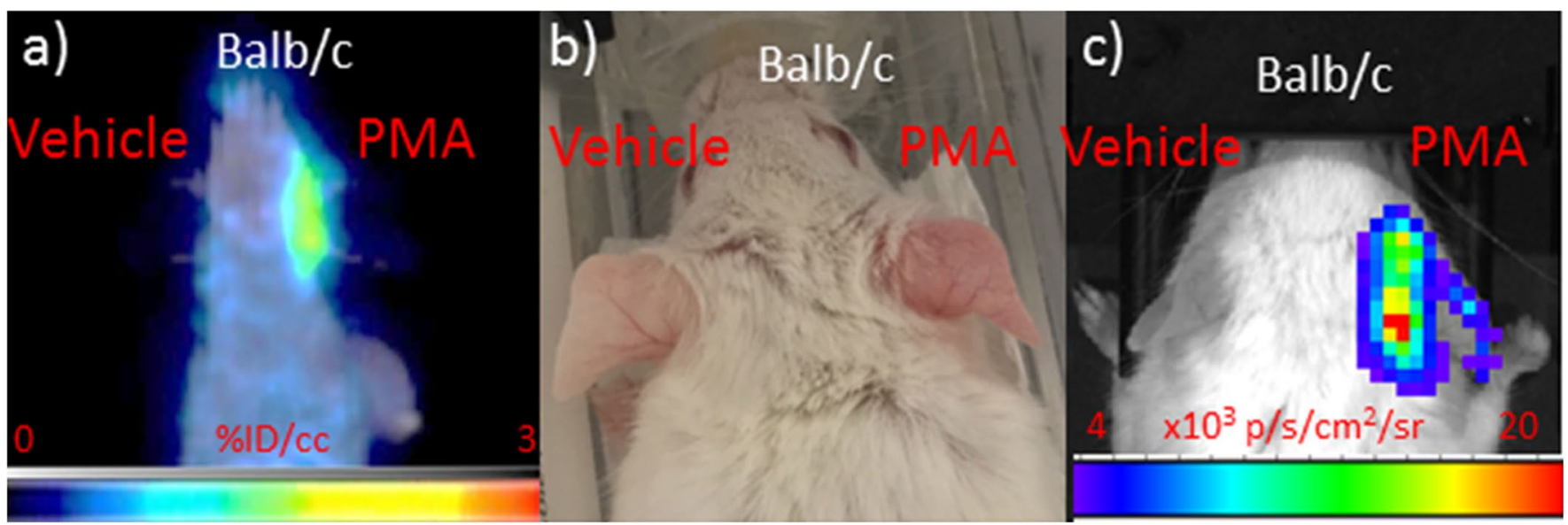

Extended Data Fig. 3 | [ ${ }^{18}$ F]4FN PET/CT in a model of mild contact dermatitis. A) BALB/CN mice were treated with either PMA or vehicle and imaged $24 \mathrm{hr}$ post treatment by $\mathrm{PET} / \mathrm{CT}$ scanning at $1 \mathrm{hr}$ post-injection (i.p.) of $\left[{ }^{18} \mathrm{~F}\right] 4 \mathrm{FN}$. B) photograph $3 \mathrm{hr}$ post $\left[{ }^{18} \mathrm{~F}\right] 4 \mathrm{FN}$ injection. C) BLI $10 \mathrm{~min}$ post luminol injection. 
A)

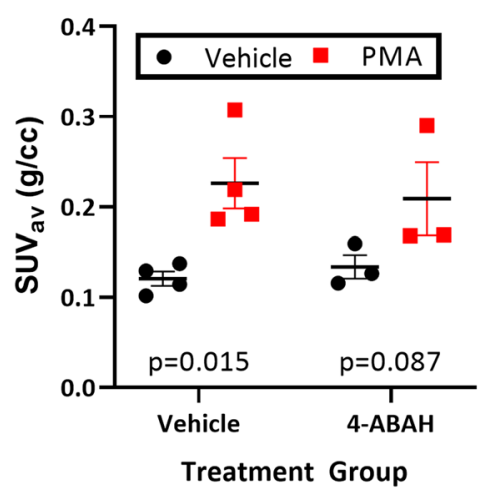

B)

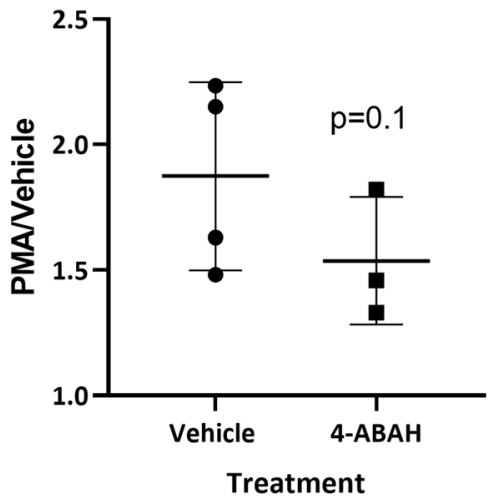

C)

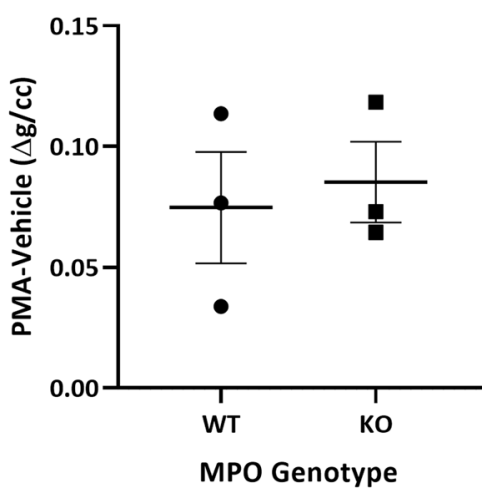

Extended Data Fig. 4 | [ $\left.{ }^{18} \mathrm{~F}\right]$ 4FN PET/CT in a model of mild contact dermatitis. A) In BALB/CN mice, 4-ABAH treatment mildly inhibited PMA-induced retention of $\left[{ }^{18} \mathrm{~F}\right] 4 \mathrm{FN}$ when compared to untreated animals. 2-way ANOVA with replication, test for interaction. B) 4-ABAH-induced inhibition appeared more evident when data were plotted as PMA/vehicle ratio showing a 50\% reduction in PMA-induced retention $(p=0.1$, one-tailed non-parametric t-test). C) In $\mathrm{Mpo}^{\circ}$ mice (KO), any effect was below the limit of detection and appeared to be compensated by another ROS-producing mechanism. Data are presented as mean $+/$ - SEM. Each point represents an individual animal. 


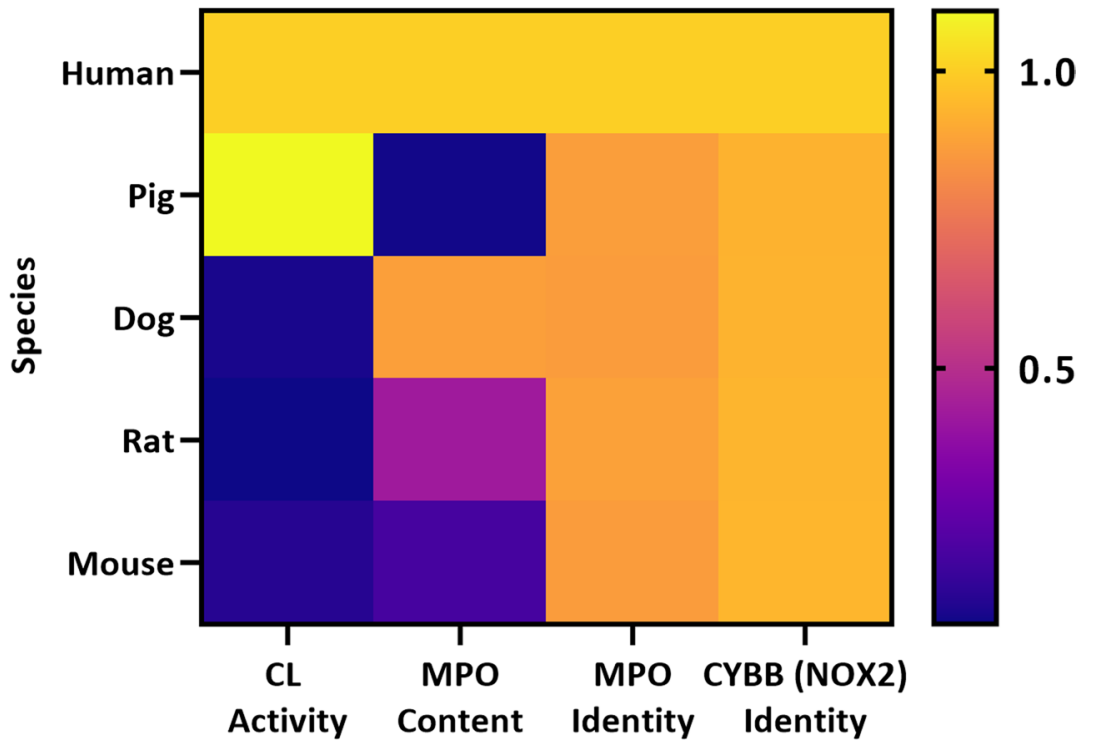

Extended Data Fig. 5 | Conservation of sequence across multiple species, but rodents underestimate MPO content and ROS burst broadly. CYBB sequence of the NOX2 complex is conserved from yeast to plant to mouse to man; MPO sequence is conserved at the vertebrate level from frogs to mouse to man, but MPO content and ROS/RNS flux (as measured by PMA-induced chemiluminescence (CL activity) through these pathways) show significant interspecies variance (data from literature reports with human activity set to unity) (Surgery 126, 248-254 (1999); J. Immunol. Methods 115, 141-147 (1988); Comp Biochem Physiol B 75, 335-340 (1983); Blood 46, 913-919 (1975)). 


\section{L-012}

כ)

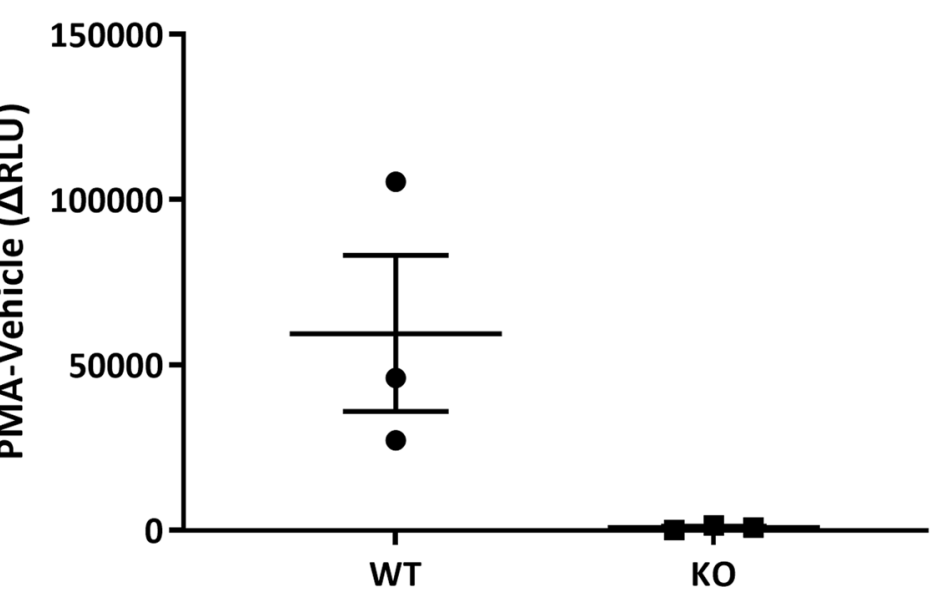

Nox2 Status $\left[{ }^{18} \mathrm{~F}\right] 4 \mathrm{FN}$

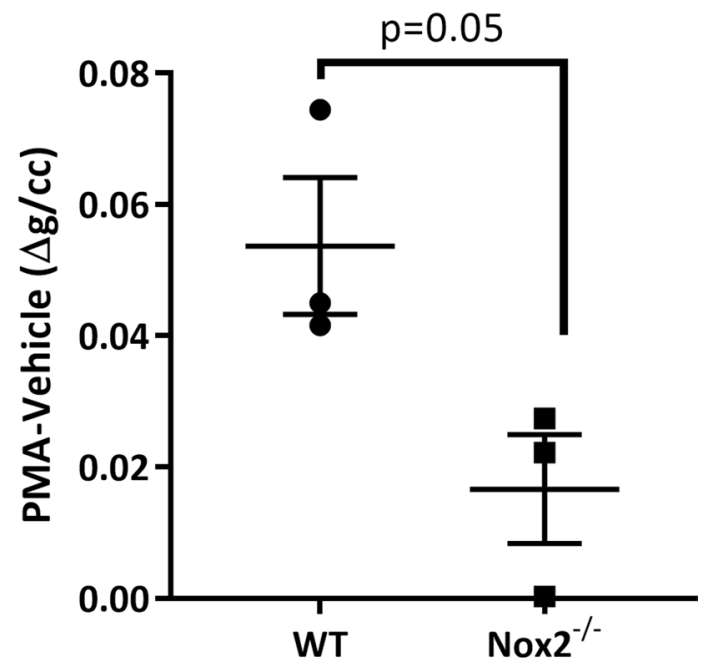

Nox2 Status

Extended Data Fig. 6 | Imaging of WT vs Nox2\% (KO) mice confirmed that the KO mice had functionally impaired RONS production as validated by L-012 BLI imaging. The right ears were treated with PMA as described and then imaged by $\left.{ }^{18} \mathrm{~F}\right] 4 \mathrm{FN}$ PET/CT. Mice were subsequently injected with L-012 i.p. ( $20 \mathrm{mg} / \mathrm{kg}$ ) and imaged for bioluminescence (IVIS SPECTRUM, Perkin Elmer). Data are presented as mean +/- SEM. Each point represents an individual animal. 
Extended Data Table 1 | Radiochemical characteristics of $\left[{ }^{18} \mathrm{~F}\right] 4 \mathrm{FN}$

\begin{tabular}{|l|l|l|l|l|l|}
\hline Compound & Yield & $\begin{array}{l}\text { Radiochemical } \\
\text { Purity (\%) }\end{array}$ & $\begin{array}{l}\text { Molar } \\
\text { Activity }\end{array}$ & $\begin{array}{l}\text { Stability 4 hr } \\
\text { (PBS/10\% } \\
\text { Ethanol) }\end{array}$ & $\begin{array}{l}\text { Stability Mouse } \\
\text { Plasma }\end{array}$ \\
\hline$\left.{ }^{18} \mathrm{~F}\right] 4 \mathrm{FN}$ & $\begin{array}{l}6.8 \pm 2.5 \% \\
(\mathrm{n}=22)\end{array}$ & $>99 \%$ & $\begin{array}{l}50-140 \\
\mathrm{GBq} / \mu \mathrm{mol}\end{array}$ & $>99 \%$ & $>99 \%$ \\
& & & & \\
\hline
\end{tabular}


Extended Data Table 2 | Medicinal chemistry properties

\begin{tabular}{|l|c|}
\hline Property & Value \\
\hline Calculated Log P (ChemAxon) & 2.8 \\
\hline Calculated pKa (ChemAxon) & 8.9 \\
\hline Molecular Weight $\left({ }^{18} \mathrm{~F}\right.$ ) & 162.163 \\
\hline \#Rotatable Bonds & 0 \\
\hline Hydrogen Bond Acceptors & 1 \\
\hline Hydrogen Bond Donors & 1 \\
\hline Rule of 5 Compliant & Yes \\
\hline Elimination Rate $\mathrm{k}_{\text {fast }}(\mathbf{1} / \mathrm{s})$ & $1.2 \times 10^{-4}\left(2.0 \times 10^{-5}\right)$ \\
\hline Elimination Rate $\mathrm{k}_{\text {slow }}(\mathbf{1} / \mathrm{s})$ & $1.5\left(1.2 \times 10^{-1}\right)$ \\
\hline Elimination Half Time $(\mathrm{hr})$ & $0.6(0.1)$ \\
\hline Vd $(\mathrm{L} / \mathrm{kg})$ &
\end{tabular}

$\left[{ }^{18} \mathrm{~F}\right] 4 \mathrm{FN}$ demonstrates favorable "drug-like" qualities, including a dual exponential clearance with $>90 \%$ of the compound clearing during the fast phase. $\mathrm{n}=4$ mice from LPS arthritis experiment. Data represent mean $+/$ - standard error of mean. 


\section{Reporting Summary}

Nature Research wishes to improve the reproducibility of the work that we publish. This form provides structure for consistency and transparency in reporting. For further information on Nature Research policies, see our Editorial Policies and the Editorial Policy Checklist.

\section{Statistics}

For all statistical analyses, confirm that the following items are present in the figure legend, table legend, main text, or Methods section.

n/a Confirmed

$\bigotimes$ The exact sample size $(n)$ for each experimental group/condition, given as a discrete number and unit of measurement

$\bigotimes$ A statement on whether measurements were taken from distinct samples or whether the same sample was measured repeatedly

$\varnothing$ The statistical test(s) used AND whether they are one- or two-sided

Only common tests should be described solely by name; describe more complex techniques in the Methods section.

$\bigotimes$ A description of all covariates tested

\ A description of any assumptions or corrections, such as tests of normality and adjustment for multiple comparisons

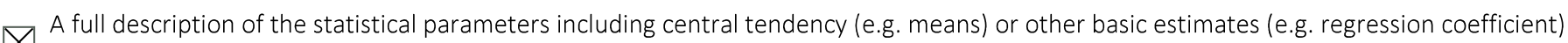

AND variation (e.g. standard deviation) or associated estimates of uncertainty (e.g. confidence intervals)

For null hypothesis testing, the test statistic (e.g. $F, t, r$ ) with confidence intervals, effect sizes, degrees of freedom and $P$ value noted

Give $P$ values as exact values whenever suitable.

Х $\square$ For Bayesian analysis, information on the choice of priors and Markov chain Monte Carlo settings

Х $\square$ For hierarchical and complex designs, identification of the appropriate level for tests and full reporting of outcomes

$\square \bigotimes$ Estimates of effect sizes (e.g. Cohen's $d$, Pearson's $r$ ), indicating how they were calculated

Our web collection on statistics for biologists contains articles on many of the points above.

\section{Software and code}

Policy information about availability of computer code

Data collection Albira Software Suite (Bruker v 5.8) for PET and CT data collection, reconstruction, and automatic fusion. Laura (v 5.0.9.74 SP3) for radio HLPC acquisition and analysis analysis.

Data analysis (PMOD (PMOD technologies v 3.5) and Graph Pad Prism (v8) for PET/CT image analysis and data analysis respectively.

For manuscripts utilizing custom algorithms or software that are central to the research but not yet described in published literature, software must be made available to editors and

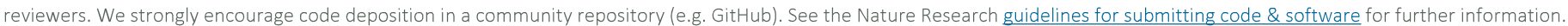

\section{Data}

Policy information about availability of data

All manuscripts must include a data availability statement. This statement should provide the following information, where applicable:

- Accession codes, unique identifiers, or web links for publicly available datasets

- A list of figures that have associated raw data

- A description of any restrictions on data availability

All data are available upon request. All relevant data are available in the main text or Supplemental Information. The data types contained herein are not typically deposited in standard repositories. "Raw" PET and CT imaging data including list mode acquisitions are stored on a backed-up pre-clinical PACS system at UT MD Anderson and are available upon request. 
Please select the one below that is the best fit for your research. If you are not sure, read the appropriate sections before making your selection.

\ Life sciences

Behavioural \& social sciences

Ecological, evolutionary \& environmental sciences

For a reference copy of the document with all sections, see nature.com/documents/nr-reporting-summary-flat.pdf

\section{Life sciences study design}

All studies must disclose on these points even when the disclosure is negative.

Sample size Sample sizes are all explicitly indicated in the figure legends or text. Sample size was selected based upon previous studies of bioluminescent reporters and the desire for large effect size for a translatable robust reporter. Robust reporters require large effect sizes to be useful and therefore should show effects in $\mathrm{N}<=5$ mice per group.

Data exclusions No individual data points were excluded from the any study or figure.

Adult C57B16/J mice rather than young C57BI6/J mice were excluded due to their mutation in Nlrp12 vs C57Bl6/N mice (Nat Commun. 2016;

7: 13180.). This mutation decreases neutrophil attraction and activation which decreases the effect size of the reporter and therefore decreases the ability to dissect an inhibitory effect. The effect was still observed in adult mice but small.

Replication $\quad$ Data were replicated as indicated in the figure legends as well as materials and methods. For in vitro radio HPLC experiments, technical replicates are included but key experiments have been replicated on independent days yielding the same results. For cell line experiments, this includes multiple technical replicates across multiple different experimental days as indicated in the text. For animal experiments, PET in vivo animal data from independent experiments with multiple individuals are all included. Indeed, significant effort was placed upon robustness by spending effort on selective uptake between mouse strains and injection routes rather than upon increasing the n's of individual experiments.

Randomization Drug treatment was not utilized so formal randomization was not conducted.

Blinding

Blinding was not relevant because the reporter is an imaging based reporter with known assymetry.

\section{Reporting for specific materials, systems and methods}

We require information from authors about some types of materials, experimental systems and methods used in many studies. Here, indicate whether each material, system or method listed is relevant to your study. If you are not sure if a list item applies to your research, read the appropriate section before selecting a response.

\begin{tabular}{l|l} 
Materials \& experimental systems \\
\hline$n / a$ & Involved in the study \\
$\square$ & $\square$ Antibodies \\
$\square$ & $\square$ Eukaryotic cell lines \\
$\square$ & $\square$ Animals and other organisms \\
$\square$ & $\square$ Clinical data \\
$\square$ & $\square$ Dual use research of concern
\end{tabular}

Methods

$\mathrm{n} / \mathrm{a}$ Involved in the study

\ $\square$ chip-seq

\ $\square$ Flow cytometry

Х $\square$ MRI-based neuroimaging

\section{Eukaryotic cell lines}

Policy information about cell lines

Cell line source(s)

HL-60 ATCC

Authentication

ATCC HL60 were utilized directly from ATCC without further authentication.

Mycoplasma contamination

Tested for mycoplasma regularly and prior to use (negative).

Commonly misidentified lines

(See ICLAC register)
HL60 are not found in the ICLAC database. 
Policy information about studies involving animals; ARRIVE guidelines recommended for reporting animal research

Laboratory animals

Balb/c NTac mice, C56BI6/ N mice from Taconic, C57BI6/J from Jackson Laboratories, Cybb Nox2 KO on C57BI6/J mice from Jackson Laboratories were utilized; and MPO-/- on a C57Bl6/J background originally from Jackson Laboratories, but bred in house and PCR confirmed for KO were utilized. These are indicated in the methods of the paper.

Wild animals

Not used

Field-collected samples

not used

Ethics oversight

IACUC protocols were regularly submitted and followed UT MD Anderson IACUC protocol 00001179

Note that full information on the approval of the study protocol must also be provided in the manuscript. 